Article

\title{
Flow Dynamics of Sulfate-Modified Water/Polymer Flooding in Micromodels with Modified Wettability
}

\author{
Muhammad Tahir *, Rafael E. Hincapie $₫$, Calvin L. Gaol, Stefanie Säfken and Leonhard Ganzer \\ Institute of Subsurface Energy Systems, Clausthal University of Technology, 38678 Clausthal-Zellerfeld, \\ Germany; hincapie.rafael@tu-clausthal.de (R.E.H.); calvin.lumban.gaol@tu-clausthal.de (C.L.G.); \\ stefanie.saefken@tu-clausthal.de (S.S.); leonhard.ganzer@tu-clausthal.de (L.G.) \\ * Correspondence: muhammad.tahir@tu-clausthal.de; Tel.: +49-179-5311435
}

Received: 26 March 2020; Accepted: 29 April 2020; Published: 7 May 2020

\begin{abstract}
This work describes the flow behavior of the oil recovery obtained by the injection of sulfate-modified/low-salinity water in micromodels with different wettabilities. It provides a detailed microscopic visualization of the displacement taking place during modified water flooding at a pore-scale level, while evaluating the effect of wettability on oil recovery. A comprehensive workflow for the evaluation is proposed that includes fluid-fluid and rock-fluid interactions. The methods studied comprise flooding experiments with micromodels. Artificial and real structure water-wet micromodels are used to understand flow behavior and oil recovery. Subsequently, water-wet, complex-wet, and oil-wet micromodels help understand wettability and rock-fluid interaction. The effect of the sulfate content present in the brine is a key variable in this work. The results of micromodel experiments conducted in this work indicate that sulfate-modified water flooding performs better in mixed-wet/oil-wet (artificial structure) than in water-wet systems. This slightly differs from observations of core flood experiments, where oil-wet conditions provided better process efficiency. As an overall result, sulfate-modified water flooding recovered more oil than SSW injection in oil-wet and complex-wet systems compared to water-wet systems.
\end{abstract}

Keywords: wettability alteration; interfacial viscoelasticity; sulfate-modified water; low-salinity water; recovery factor

\section{Introduction}

The concept of smart/modified water flooding was first proposed by Morrow et al. [1]; leading to further investigations with regards to the impact of injected water composition on oil recovery [2-9]. In simple words, smart/modified water flooding deals with either the addition of active ions/salts or removal of in-active ions/salts from the injection brine. This addition or removal of some specific salts changes not only the salinity but also the hardness of the brine $[10,11]$. Active and non-active ions are known as potential determining ions (PDI) and non-PDI, respectively [12], and their impact on oil recovery have already been investigated by researchers [12,13]. The manipulation of injected brine composition is believed to be able to disturb the established rock-oil-brine (ROB) equilibrium, and detach the oleic polar compounds from the rock surface. Gomari et al., Karoussi and Hamouda and Tahir et al. [14-16] showed that sulfate, as the most effective PDI, helps to detach the long chain carboxylic group from the oil-wet surface, and control the further adsorption of these compounds on the rock surface.

Clay and quartz content in the rock matrix are negatively charged surfaces, whereas oil can have positively or negatively charged compounds. The negative polar compounds of oil are attached to rock-surface with the divalent ions bridging $\left(\mathrm{Ca}^{2+}\right.$ and $\mathrm{Mg}^{2+}$ present in formation brine) [17], as shown in Figure 1A. The positive polar compounds of the oil are attached to the negatively charged rock 
surfaces, and the created chemical bondage results in the oil wetting condition of the sandstone reservoir. The negative polar compounds of the oil are replaced by $\mathrm{SO}_{4}{ }^{2-}$ through $\mathrm{Ca}^{2+}$ and $\mathrm{Mg}^{2+}$, causing bridging of the rock surface, and subsequently altering wettability towards a water-wet state, as presented in Figure 1B. However, the wettability alteration process is catalyzed if low salinity sulfate-modified water flooding is performed. Low salt will further dilute the divalent cations in the formation brine, and hence weaken the bondage force.

\section{(A)}
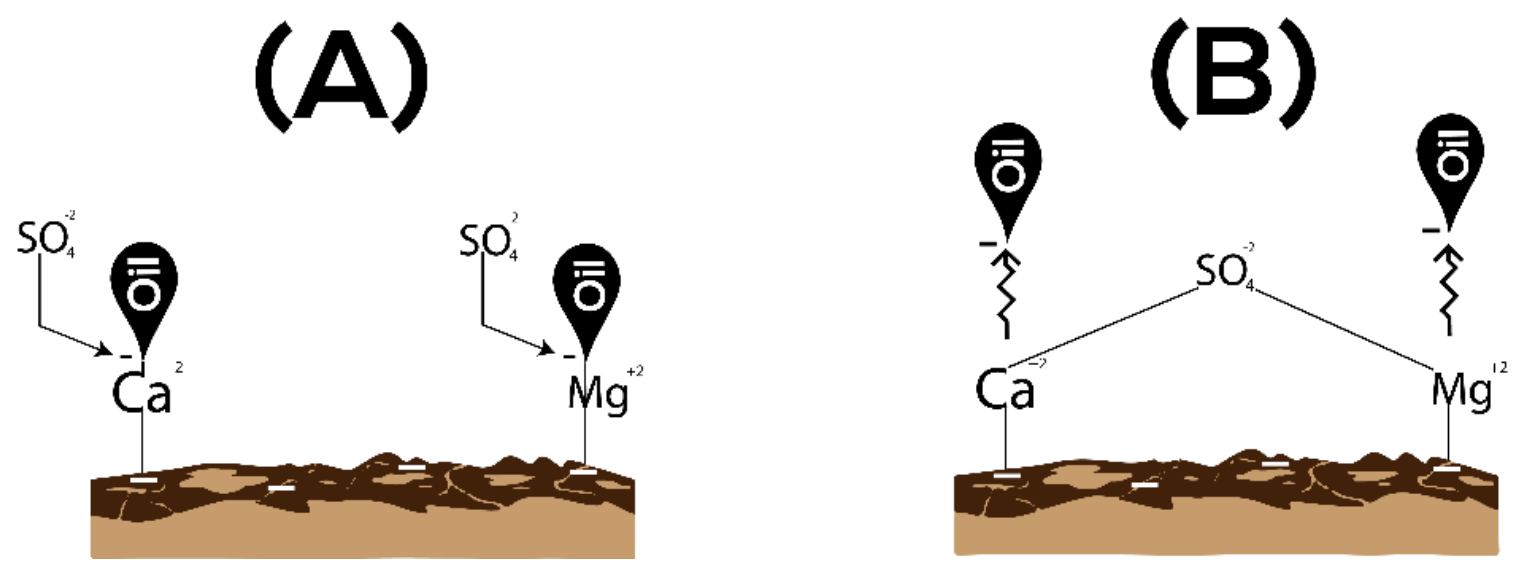

Figure 1. Wettability alteration mechanism of sulfate in sandstone. (A) refers to oil-wet; (B) refers to water-wet condition of reservoir.

Interfacial interaction between fluids is another recovery mechanism responsible for the additional oil recovery during modified water flooding [18-20]. This interfacial interaction (layer) is developed at the oil-brine interface (fluid-fluid interaction) that resulted from the ionic activity between the modified brine and oil polar compounds [21,22]. However, this layer is sensitive to the salinity of injected brine. Mahzari and Sohrabi [23], Morin et al. [24] and Sohrabi et al. [25] demonstrated that low salinity flooding produces a more stable and viscoelastic surface at the oil-brine interface. For instance, Morin et al. [24] found that this stable layer is resistant to rupture, and assists the continuous oil phase transportation in the porous media, hence it contributes to the higher oil recovery.

Based on the common recovery mechanisms of wettability alteration, multicomponent ion exchange (MIE) and change in $\mathrm{pH}$ and clay swelling [26-29], some researchers refer to low salinity flood (LSF) and smart/modified water flood (SWF) as the same technology [30]. Others believe both technologies are completely different, based on the microscale ionic activity between fluid-fluid interactions [31,32]. Further developments of smart/modified water technology led to the concept of interfacial viscoelasticity (IFV) at the fluids interface as the main recovery mechanism $[16,20,22,33-36]$. Table 1 reviews a list of studies that deal with interfacial interaction between oil and brine, and investigate its impact on oil recovery from sandstone and carbonates.

We have addressed this topic in a previous work, where the results of IFV are presented for the same oil sample and different brine compositions used in this work [32]. With the gathered observations, it was concluded that a spiked amount of $\mathrm{SO}_{4}{ }^{2-}$ worked effectively to design modified water, possibly contributing to the additional oil. Additional evaluations also helped us to find the difference between low salinity and modified water through core plugs and the role of PDI and non-PDI ions [10,32]. 
Table 1. Studies with focus on interfacial-interaction as a potential recovery mechanism.

\begin{tabular}{|c|c|c|c|c|c|}
\hline No. & Mechanism & Approach & Formation & Active Salts & Ref. \\
\hline 1 & $\begin{array}{l}\text { Wettability alteration, } \\
\text { DLE, Oil-brine int. }\end{array}$ & $\begin{array}{l}\text { Spontaneous imbibition, } \\
\text { Interfacial rheology }\end{array}$ & Sandstone & $\begin{array}{l}\mathrm{SO}_{4} \text {, Low salt brine } \\
(36,600-5460 \mathrm{ppm})\end{array}$ & [19] \\
\hline 2 & $\begin{array}{l}\text { Oil-brine interfacial } \\
\text { interactions }\end{array}$ & $\begin{array}{l}\text { Interfacial viscoelasticity, } \\
\text { Core flooding }\end{array}$ & Sandstone & $\begin{array}{l}\mathrm{SO}_{4}, \text { Low salt brine } \\
(1-10 \% \text { of } 0.674 \mathrm{M})\end{array}$ & [37] \\
\hline 3 & $\begin{array}{l}\text { Oil-brine interfacial } \\
\text { interactions }\end{array}$ & IFT & N/A & $\begin{array}{l}\mathrm{Ca}, \mathrm{Mg}, \mathrm{Na}, \mathrm{SO}_{4} \\
(5760 \mathrm{ppm})\end{array}$ & [38] \\
\hline 4 & $\begin{array}{l}\text { Oil-brine interfacial } \\
\text { interactions }\end{array}$ & Core flooding & Carbonate & $\begin{array}{l}\mathrm{SO}_{4} \text {, Low salt brine } \\
(3535-37,102 \mathrm{ppm})\end{array}$ & [39] \\
\hline 5 & $\begin{array}{l}\text { Oil-brine interfacial } \\
\text { interactions }\end{array}$ & $\begin{array}{l}\text { Langmuir Trough, Oil } \\
\text { drop Volume, G', } \mathrm{G}^{\prime \prime} \\
\text { Moduli }\end{array}$ & N/A & $\begin{array}{l}\mathrm{SO}_{4} \text {, Low salt brine } \\
\text { (5761-16,407 ppm) }\end{array}$ & {$[40]$} \\
\hline 6 & Wettability alteration & Core flooding, IFT & $\begin{array}{l}\text { Sandstone and } \\
\text { Carbonates }\end{array}$ & Low salt brine & {$[41]$} \\
\hline 7 & $\begin{array}{c}\text { Wettability alteration, } \\
\text { PH-value }\end{array}$ & $\begin{array}{l}\text { Core flooding, Sand-pack, } \\
\text { crushed sand }\end{array}$ & Sandstone & $\begin{array}{l}\text { Low salt brine } \\
\quad(710 \mathrm{ppm})\end{array}$ & {$[42]$} \\
\hline 8 & Wettability alteration & Core flooding & Sandstone & $\begin{array}{l}\text { Softened Formation } \\
\text { brine }(\mathrm{Ca}, \mathrm{Mg})\end{array}$ & {$[43]$} \\
\hline 9 & IFT & IFT & N/A & $\mathrm{Ca}, \mathrm{SO}_{4}$ & [44] \\
\hline
\end{tabular}

According to the literature, the basic requirements for a successful application of low salinity and modified water flood are the same and can be summarized as:

(1) Reservoir should be oil-wet/mix-wet $[12,45,46]$. In an oil-wet/intermediate-wet state, oil polar compounds are attached to the rock surface through ionic interactions. Low-salinity/modified water flooding targets these polar compounds, detaching them from the rock surface, as shown in Figure 1, and hence producing additional oil recovery through wettability alteration from oil-wet/intermediate-wet to water-wet.

(2) Existence of polar compounds in the oil $[35,47,48]$. Polar compounds are mainly composed of asphaltene and naphthenic acids (NAs), and act as surface active compounds. These two surface active compounds are known not only to stabilize water-in-crude oil emulsions, but also to constitute the interfacial film at the fluid-fluid interface. Asphaltene is insoluble in low molecular weight alkanes (n-heptane or n-pentane), but soluble in aromatics (toluene). The interfacial viscoelastic layer at the brine-oil interface is produced, due to the slow and irreversible adsorption process of asphaltene at the fluid interface [20-22]. Acevedo et al. [49] described the positive effects of asphaltene to develop the oil-brine interface's rheological properties. Another fraction of crude oil is NAs which are composed of cycloaliphatic carboxylic acids (R-COOH) $[47,50]$. These NAs are hydrophilic compounds and are accumulated at the oil-brine interface. Further, NAs can also dissociate in the aqueous phase and reach cations present in the brine to form naphthenic salts. These salts can accumulate at the oil-brine interface. However, the role of NAs remains uncertain because some studies claim that NAs improve oil-brine interface elasticity [47], while others claim they soften the interfacial film [51].

(3) High content of divalent cations in the formation brine [2,52]. Divalent cations provide the bridging connection between negative oil polar compounds and negative-charged rock surface. Mainly, $\mathrm{Ca}^{2+}, \mathrm{Mg}^{2+}$ play a significant role to create a bond [17], as shown in Figure 1.

Previously, experiments were performed using core plugs and sand-packs to prove the effectiveness of modified water technology [43,53]. A study from Aghaeifar et al. [54] reveals that injecting modified water in the secondary mode is an intelligent approach, compared to the injection in the tertiary mode. Further, the synergies of modified water in combination with other EOR technologies have also presented the concept of efficient hybrid EOR technologies [55-58]. Modified water and low salinity water flooding in combination with polymer flood showed promising oil recovery results based on the improved sweep efficiency. This work focuses on describing the flow behavior of 
oil recovery from the injection of low-salinity/sulfate-modified water in combination with polymer. It provides a detailed microscopic visualization and macroscopic observations of the displacement taking place during modified water flooding at a pore-scale level, while evaluating the effect of fluid-fluid/rock-fluid interactions on oil recovery. On one hand, modified water will affect the microscopic sweep efficiency by triggering fluid-fluid and rock-fluid interactions. On the other hand, polymer flooding is expected to improve the macroscopic sweep efficiency, due to a favorable displacement mobility ratio. Hence, the hybrid process is expected to provide the combined benefits of both EOR methods. Modified/low-salinity water injection as a pre-flush is expected to change the reservoir wettability from oil-wet to water-wet and change the fluid distribution in the reservoir. Detached oil droplets are expected to move from small pores to large or medium pores. Polymer flooding after modified brine is expected to produce the redistributed oil phase easily, due to improved sweep efficiency. Low-concentration polymer solutions will be required for a combination with a pre-flush of modified water, which will decrease the cost of EOR projects. Haghighi et al. [59] presented that mixing of surfactant solution in sulfate-modified water could lead to optimum oil recovery.

This study is the extension of previous experiments performed in another stage of the research $[10,32]$. In this work, microfluidics are used as an approach to justify/understand the results previously obtained while flooding modified water through sandstone cores (core flooding). In addition, micromodel observations are also expected to facilitate the description of the fluid flow dynamics taking place at the microscopic scale. The same fluids as previous publications are utilized, but experiments are performed at a room temperature of $22^{\circ} \mathrm{C}$. Finally, data obtained from the microfluidics flooding in this study are cross analyzed with the core floods data to draw underlying conclusions.

\section{General Methodology and Approach}

The proposed workflow, as shown in Figure 2, helps to create an understanding of the role of the fluid-fluid interfacial interaction as a recovery mechanism other than a wettability alteration. Furthermore, an attempt is made to analyze the success of the mechanism of a hybrid EOR comprising modified water application, in combination with a polymer flood. The following steps were completed to achieve the objectives of this study:

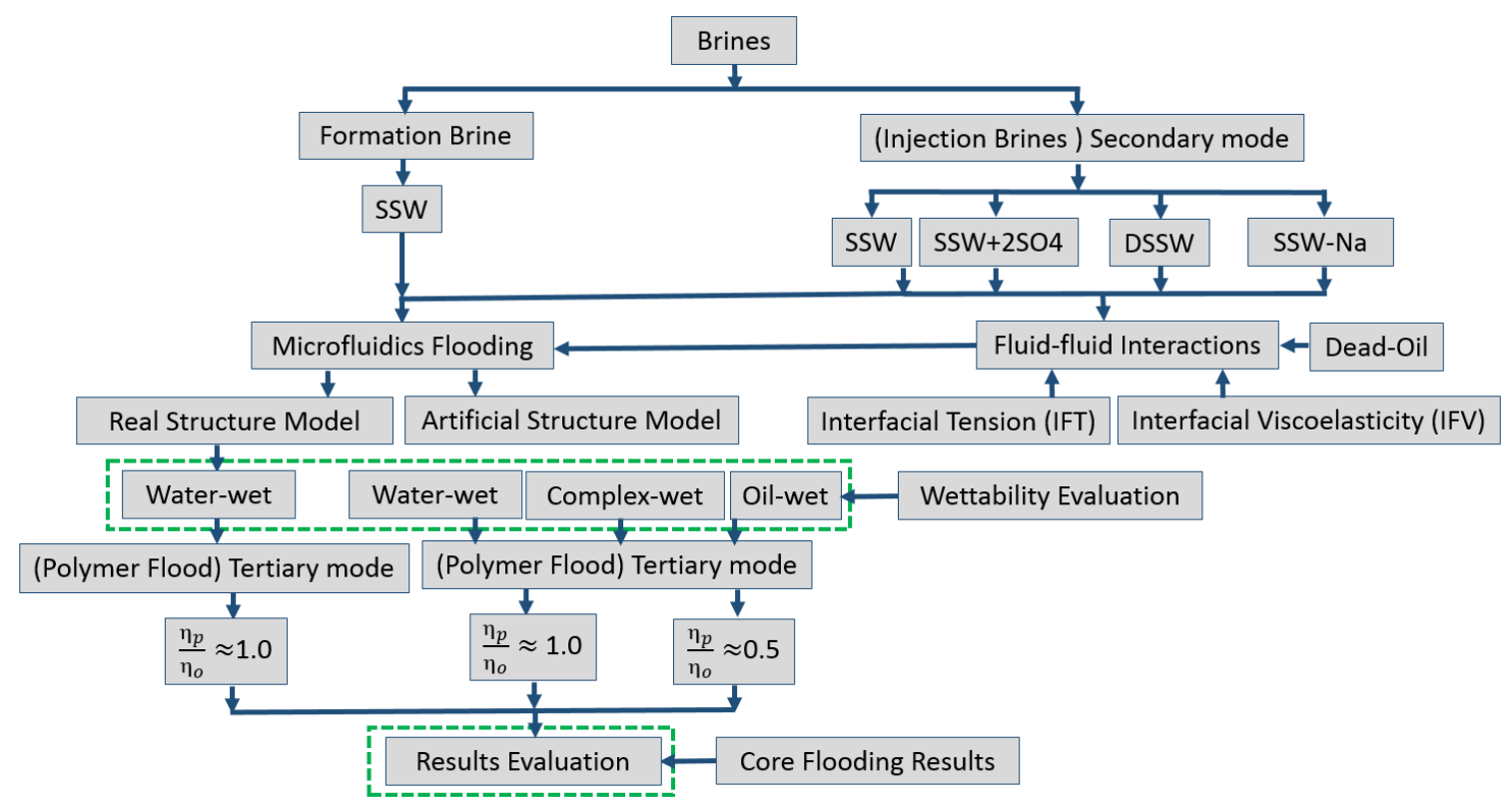

Figure 2. Adopted workflow in the research for the hybrid enhanced oil recovery (EOR) process evaluation.

Brine Preparation and Optimization: Four different injection brines were prepared to correlate and cross-validate the fluid-fluid interaction and oil recovery results. The amount of sulfate in the brine and TDS were the key parameters for comparison. 
Polymer Diluted Solutions Preparation: Polymer solutions with an oil-to-polymer viscosity ratio of 1 and 2 at a shear rate $10 \mathrm{~s}^{-1}$ were prepared to inject in the tertiary mode for viscosity control.

Interfacial Tension and Interfacial Viscoelasticity Evaluations: Define the ionic activity and chemical interactions between oil polar compounds and four different brines at the liquid-liquid interface.

Wettability and Geometry of the Porous Media: Micromodels with three wettability conditions were used to investigate the role of wettability on the fluid-fluid interfacial interaction. Moreover, two types of water-wet micromodels with different rock geometries/characteristics were further investigated to cross-analyze the results.

Two-phase Modified Brine Injection combined with Polymer Flooding in Micromodels: Flooding experiments were performed with oil-saturated micromodels with an established initial water saturation. Brines were injected as the secondary mode, and polymer flooding was performed in the tertiary mode, with a mix-wet micromodel to evaluate and define the benefits and synergies of the combined EOR process.

Secondary Mode Brine Flooding Comparison of Micromodels and Aged Core Plugs: A comparison was made between the recovery factors obtained from mixed-wet micromodel and aged core plugs, in order to understand and elucidate the fluid-fluid interaction as the recovery mechanism.

\section{Materials and Methods}

\subsection{Fluids and Chemicals}

\subsubsection{Brines}

Brines were prepared by mixing different salt components in deionized water. Synthetic seawater (SSW) was used as the base brine (Brine 1), while sulfate-modified water was prepared by doubling the amount of sulfate of SSW (Brine 2). A third brine was prepared by diluting the SSW 10 times to achieve TDS $\approx 5 \mathrm{~g} / \mathrm{L}$ (Brine 3). The fourth injection brine (Brine 4 ) was prepared by mixing all the salts of SSW except $\mathrm{NaCl}$. Brine 4 was used to investigate the role of potential determining ions (PDI) in the formation brine and the removal of non-PDI from injection brine, as studied previously [32]. The chemical compositions of brines are described in Table 2. The filtration of all brines was performed at room temperature by applying $\sim 40 \mathrm{psi}$ ( 2.76 bar) $\mathrm{N}_{2}$ gas pressure using a $0.2-\mu \mathrm{m}$ MF-Millipore Membrane Filter, in order to avoid any undissolved solvent or small particles. The pore structure of the micromodels used in this work tend to be sensitive to undissolved components, and this can cause severe pore plugging/injectivity problems.

Table 2. Chemical composition of formation and injection brines.

\begin{tabular}{|c|c|c|c|c|c|}
\hline \multirow{4}{*}{ Chemical Formula } & \multicolumn{5}{|c|}{ Total Dissolved Solids (g/L) } \\
\hline & \multirow{2}{*}{$\begin{array}{c}\text { Formation Brine } \\
\text { Brine } 1\end{array}$} & \multicolumn{4}{|c|}{ Injection Brines } \\
\hline & & Brine 1 & Brine 2 & Brine 3 & Brine 4 \\
\hline & SSW & SSW & $\mathrm{SSW}+2 \mathrm{SO}_{4}{ }^{2-}$ & 10DSSW & SSW-Na \\
\hline $\mathrm{NaCl}$ & 23.97 & 23.97 & 23.97 & 2.39 & 0.00 \\
\hline $\mathrm{KCl}$ & 0.80 & 0.80 & 0.80 & 0.08 & 0.80 \\
\hline $\mathrm{CaCl}_{2} \cdot 2 \mathrm{H}_{2} \mathrm{O}$ & 1.11 & 1.11 & 1.11 & 0.11 & 1.11 \\
\hline $\mathrm{MgCl}_{2} \cdot 6 \mathrm{H}_{2} \mathrm{O}$ & 11.04 & 11.04 & 11.04 & 1.10 & 11.04 \\
\hline $\mathrm{SrCl}_{2} \cdot 6 \mathrm{H}_{2} \mathrm{O}$ & 0.03 & 0.02 & 0.03 & 0.003 & 0.03 \\
\hline $\mathrm{Na}_{2} \mathrm{SO}_{4}$ & 3.93 & 3.93 & 7.86 & 0.39 & 3.93 \\
\hline $\mathrm{NaHCO}_{3}$ & 0.27 & 0.27 & 0.27 & 0.03 & 0.27 \\
\hline TDS & 41.15 & 41.15 & 45.09 & 4.11 & 17.18 \\
\hline Hardness & 0.13 & 0.13 & 0.11 & 0.13 & 0.48 \\
\hline Density $\left(\mathrm{g} / \mathrm{cm}^{3}\right)$ at $22{ }^{\circ} \mathrm{C}$ & 1.03 & 1.03 & 1.02 & 0.98 & 1.02 \\
\hline
\end{tabular}




\subsubsection{Oil}

Dead crude oil (TAN is $1.15 \mathrm{mg} \mathrm{KOH} / \mathrm{g}$ ) after centrifuged and degasification was used for oil recovery experiments. Oil properties measured at $22{ }^{\circ} \mathrm{C}$ are density $\left(\mathrm{g} / \mathrm{cm}^{3}\right) 0.88,29.42{ }^{\circ}$ API gravity, $\eta_{\mathrm{o}}$ (mPa·s) $23.00[10]$.

\subsubsection{Polymer Solutions}

Diluted polymer solutions were prepared using a synthetic and high molecular weight viscoelastic polymer supplied by SNF Floerger-Flopaam 6035 S. Diluted solutions were prepared mixing a 5000 ppm stock solution with Brine 1 and Brine 2 of Table 2, using the approach adopted by Hincapie and Ganzer [60]. Two polymer concentrations (1000 ppm and $1500 \mathrm{ppm}$ ) were selected considering the desired viscosity values. The $1000 \mathrm{ppm}$-diluted solution resulted in viscosity half of the oil viscosity, while the $1500-\mathrm{ppm}$ solution equals the oil viscosity at $22^{\circ} \mathrm{C}$. Filtration of the solutions was performed to avoid fish eyes using the 5.0- $\mu \mathrm{m}$ MF-Millipore Membrane Filter.

\subsection{Interfacial Tension (IFT) Measurements}

Fluids (Oil and brines) used for this study were used in previous work [10,32]. Oil-brine IFT measurements were performed to investigate the impact of brine chemistry (monovalent and divalent ions) at the oil-brine interface. The measurements were performed using the Du Noüy ring method (Prozessor-Tensiometer KRUESS GmbH K12) at a room temperature of $22{ }^{\circ} \mathrm{C}$.

\subsection{Interfacial Viscoelastic Response (IFV)}

Interfacial viscoelastic properties between oil-brine phases were measured through the analysis of oil drop volume at the snap-off point. This approach did not provide direct measurements of interfacial viscoelasticity or elastic moduli. Rather, it provided an indirect measurement of oil-drop size analysis at the snap-off point, which correlated to the interfacial viscoelasticity. The IFV response was defined using the following steps:

- $\quad$ An oil-drop of $2.5 \mu \mathrm{L}$ volume was produced through a syringe in the specific brine phase.

- A settlement time of $10 \mathrm{~min}$ was established for ionic equilibrium between both fluids. During this time, the ionic interaction between the oil polar compounds and brine divalent/monovalent ions was expected to happen at the interface.

- After a 10 min time interval, $2.5 \mu \mathrm{L}$ of oil was further injected to increase the oil-drop size.

- An additional $10 \mathrm{~min}$ were required until the expected ionic interaction between both phases was established.

- Subsequently, $2.5 \mu \mathrm{L}$ of oil was injected to increase the oil-drop volume further. This process continued until the oil-drop snap-off happened from the needle.

- The oil-drop experienced two opposite forces before snap-off happens. One force was the buoyancy force acting upwards due to oil density. The second force was the interfacial viscoelasticity acting downwards, establishing the oil drop attachment to needle and controlling the oil-drop snap-off. The oil-drop size went on increasing in case the viscoelastic force at the interface was higher than the buoyancy force.

- After a specific increase in drop size, the buoyancy force dominates the viscoelastic force and oil drop detachment happens from the needle.

This investigation helped to study the formation of the viscoelastic layer at the fluids interface due to ionic reactions. The strong viscoelastic layer was expected to produce a more significant oil-drop volume before the snap-off point. Morin et al. [24] and Mohamed and Alvarado [61] demonstrated that the elastic interfacial film was found to be more stable and resistant to snap off. This assisted the stable and continuous oil flow during flooding, while limiting the oil trapping in porous media, hence the correlation of the higher oil recovery during core flooding experiments. 


\subsection{Porous Media/Microfluidics}

Two different glass-silicon-glass (GSG) micromodels based on pore structures were used for this study as porous media for the flooding experiments shown, as shown in Figure 3. The first micromodel type is named the artificial structure micromodel or homogeneous micromodel, due to its random distribution of circular grains. Such micromodels have been previously used for several EOR investigations [62-64]. The second type of micromodel is referred to as the real structure micromodel or heterogeneous micromodel. Its structure is based on a $\mu \mathrm{CT}$ image of a Bentheimer core plug. The real structure model has three different permeability zones, two lower permeability zones on the sides and a high permeability zone in the middle. Both micromodel types were previously used for microbial flooding experiments by Gaol et al. [62]. Pore structure images and dimensional measurements of both models are shown in Figure 3, while porosity and permeability values are given in Table 3.

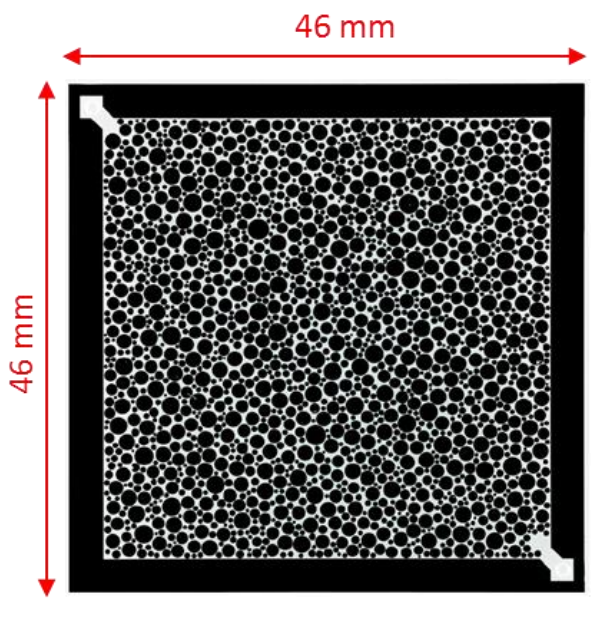

A

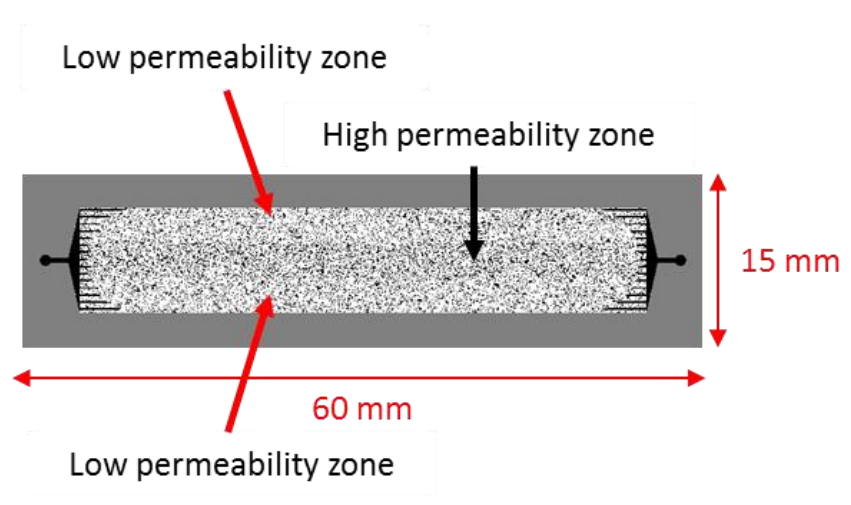

B

Figure 3. Micromodels used in this study. (A) artificial-structure (B) real-structure micromodel [40].

Table 3. Porous Media characteristics of micromodels used in this work.

\begin{tabular}{ccc}
\hline \multirow{2}{*}{ Parameter } & Glass-Silicon-Glass (GSG) & Micromodel \\
\cline { 2 - 3 } & Artificial & Real \\
\hline Porosity $(\%)$ & 27.60 & 19.20 \\
Brine Permeability $(\mathrm{mD})$ & $13,000.00$ & 1237.00 \\
Min. Pore diameter $(\mu \mathrm{m})$ & 8.00 & 12.21 \\
Max. Pore diameter $(\mu \mathrm{m})$ & 2610.00 & 112.52 \\
Avg. Pore diameter $(\mu \mathrm{m})$ & 178.20 & 31.50 \\
\hline
\end{tabular}

\subsubsection{Wettability Evaluation}

To investigate the effect of wettability, micromodels were chemically modified to generate three types, based on the presented structures, namely: water-wet, oil-wet and complex-wet/mixed-wet, as shown in Table 4. Complex/mixed wettability type deals with the local variation of wettability areas, some parts/zones were oil-wet, while others were water-wet.

The wettability alteration is achieved by a chemisorption of a fluorinated silane, applied on the micromodels inner glass and silicon surfaces. Silicon and glass are initially water-wet, with a contact angle (water) below $\sim 20^{\circ}$. After treatment, this angle is increased up to $112^{\circ}$. The oil contact angle of the modified surface is significantly lower with $77^{\circ}$. The mixed-wet micromodel is obtained by fragmentary, acid-induced abrasion of the coating. Wettability treatment with fluorinated silane is almost permanent. Only very strong acids and bases can attack the adsorbed layers. Silane does not decompose in the presence of crude oils, as proven by a stability test at $120^{\circ} \mathrm{C}$ for $8 \mathrm{~h}$. 
Table 4. Description of micromodels according wettability approach.

\begin{tabular}{ccc}
\hline \multirow{2}{*}{ Parameter } & \multicolumn{2}{c}{ Glass-Silicon-Glass (GSG) Micromodel } \\
\cline { 2 - 3 } & Artificial & Real \\
\hline Water-wet & $\sqrt{ }$ & $\sqrt{ }$ \\
Oil-wet & $\sqrt{ }$ & - \\
Complex/Mix-wet & $\sqrt{ }$ & - \\
$\mathrm{Q}(\mu \mathrm{L} / \mathrm{min})$ & 0.3 & 0.1 \\
Bump rate $(\mu \mathrm{L} / \mathrm{min})$ & 1.5 & 0.5 \\
\hline
\end{tabular}

\subsubsection{Microfluidics Setup and Flooding Approach}

For flooding experiments, the InspIOR microfluidics-flooding rig from HOT Microfluidics was used. A compacted experimental set-up that includes injection pumps, a micromodel holder, a DSLR camera for imaging, pressure sensors (connected to inlet and outlet of the micromodel holder), fluids reservoir and waste collector. Experimental set-up and components of this device are briefly described by Schumi et al. [64]. Flooding process is performed at an injection flux of $1.0 \mathrm{ft} / \mathrm{day}$, with the corresponding injection rates included in Table 4 . The bump rate injection was performed at a flux rate of $5.0 \mathrm{ft} /$ day. Flooding experiments were performed at the room temperature of $22^{\circ} \mathrm{C}$, and a system pressure of 1.0 bar (gas), with the following steps:

- The micromodel was installed in the holder, and the water injection was performed to remove air bubbles and pursued, until the differential pressure stabilized;

- Brine flooding was performed to measure the permeability of the model;

- Oil saturation was established through continuous and increasing oil injection rates until no further water could be produced;

- A two-hour stabilization interval was provided to establish a possible ionic reaction in the model;

- Brine flooding was performed to observe the oil recovery and pressure data;

- During the flooding process, images were gathered/captured at different time intervals, and recovery analysis was performed through an imaging processing tool developed in MATLAB.

\subsection{Bentheimer Core Plugs}

Bentheimer sandstone core plugs were used for the flooding experiments. A summary of the core plugs characteristics and obtained results are shown in Table 5, and further discussions and details can be seen in our previous work [32]. For comparison purposes, the results of the core plugs with only SSW as a formation brine and SSW, $\mathrm{SSW}+2 \mathrm{SO}_{4}{ }^{2-}$ and SSW-0Na as the injection brines were used.

Table 5. Summary of selected core flooding results and comparison of obtained recoveries, data presented in [31].

\begin{tabular}{|c|c|c|c|c|c|c|c|c|c|c|c|c|c|c|}
\hline Nr. & $\begin{array}{l}\text { Form. } \\
\text { Brine }\end{array}$ & Inj. Brine & $\begin{array}{l}\text { Core } \\
\text { Name }\end{array}$ & $\Phi$ & $\begin{array}{c}\text { k, } \\
\text { brine }\end{array}$ & Soi & $\begin{array}{c}\text { RF } \\
\text { Sec. } \\
\text { Mode }\end{array}$ & $\begin{array}{c}\text { Injected } \\
\text { PV }\end{array}$ & $\begin{array}{c}\text { RF } \\
\text { Bump } \\
\text { Rate }\end{array}$ & $\begin{array}{c}\text { Injected } \\
\text { PV }\end{array}$ & $\begin{array}{c}\text { RF } \\
\text { Tert. } \\
\text { Mode }\end{array}$ & $\begin{array}{c}\text { Injected } \\
\text { PV }\end{array}$ & $\begin{array}{c}\text { Total } \\
\text { RF } \\
(\%)\end{array}$ & $\begin{array}{c}\text { ROS } \\
(\%)\end{array}$ \\
\hline 2 & \multirow[t]{2}{*}{ SSW } & $\mathrm{SSW}+2 \mathrm{SO}_{4}^{2-}$ & $\mathrm{T} 7$ & 26.76 & 1952 & 82.11 & 45.69 & $\approx 3$ & 7.07 & $\approx 3$ & 8.84 & $\approx 3$ & 61.60 & 38.40 \\
\hline 4 & & SSW-ONa & $\mathrm{T} 1$ & 27.18 & 2148 & 79.39 & 32.01 & $\approx 3$ & 14.95 & $\approx 3$ & 12.56 & $\approx 3$ & 59.52 & 40.48 \\
\hline
\end{tabular}

\section{Results and Discussion}

\subsection{Fluids Optimization and Micromodel Wettability}

\subsubsection{Steady Shear Viscosity}

Figure 4 shows the steady shear viscosity of polymer solutions injected in the tertiary mode (after brine flooding). As mentioned earlier, two concentrations of $1000 \mathrm{ppm}$ and $1500 \mathrm{ppm}$ diluted solutions 
were selected, based on the viscosity selection. The 1000-ppm diluted solution had half the viscosity of the oil, while the 1500-ppm diluted solution had almost the same viscosity as the oil at a shear rate of $10 \mathrm{~s}^{-1}$. Table 6 presents the shear viscosity values at a shear rate of $10 \mathrm{~s}^{-1}$. The same concentration of polymers was also prepared in sulfate-modified water. As described in our previous work [10,32], the viscosity contrast was not substantial, both with and without sulfate.

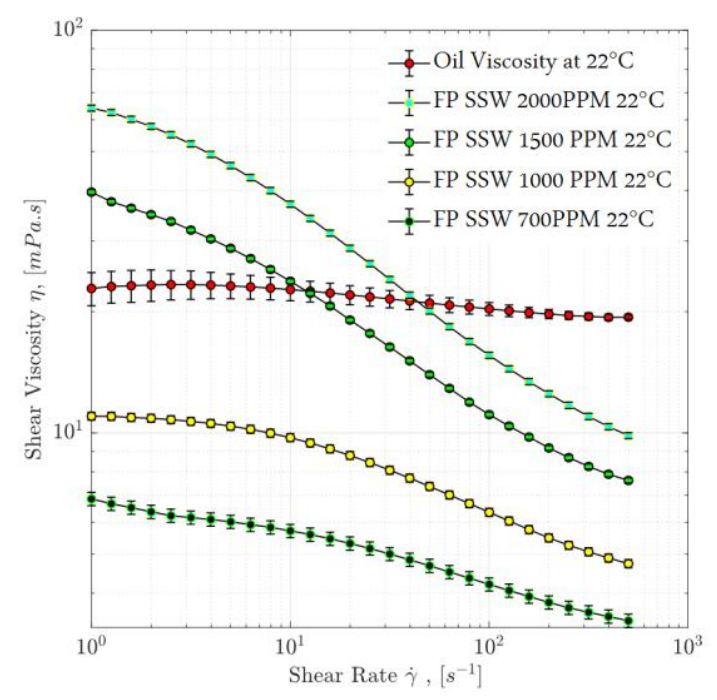

Figure 4. Shear viscosity of polymer solutions at temperature of $22{ }^{\circ} \mathrm{C}$.

Table 6. Polymer concentrations and viscosity at a shear rate of $10 \mathrm{~s}^{-1}$.

\begin{tabular}{cc}
\hline \multicolumn{2}{c}{ HPAM Polymer at $\mathbf{2 2}{ }^{\circ} \mathbf{C}$} \\
\hline Concentration $(\mathbf{p p m})$ & $\boldsymbol{\eta}$ at $\mathbf{1 0 ~} \mathbf{~ s}^{\mathbf{- 1}}[\mathbf{m P a} \cdot \mathbf{s}]$ \\
\hline 700 & 5.56 \\
1000 & 9.58 \\
1500 & 23.58 \\
2000 & 36.54 \\
Dead Oil & 21.71 \\
\hline
\end{tabular}

\subsubsection{IFT Results}

Table 7 represents the static interfacial tension measurements between brines and dead oil. Results show that the amount of total dissolved solids have a significant impact on IFT. The lowest values are measured for the SSW and SSW $+4 \mathrm{SO}_{4}{ }^{2-}$. Table 7 also shows that doubling the amount of sulfate in SSW also doubled the IFT values, and then a further increase in sulfate reduced the static IFT at the fluids interface. Moreover, diluted brine resulted in the highest values of IFT for DSSW brine. Results are in agreement with Sohrabi et al. [25], who concluded that the interfacial viscoelastic layer is more stable and elastic in the case of low salt brine. For this IFT, the response also predicts the ionic reaction between brine and oil at the interface. Active ionic interaction at the fluid-fluid interface is expected to develop the bondage of divalent ions in brine, and polar compounds in oil [23-25]. The interaction results in the development of the viscoelastic layer at the interface, and hence results in the increased IFT values.

Higher IFT enhances the development of the elastic layer at the interface and corresponds to higher recovery $[24,61]$. But increasing the amount of sulfate four times in SSW results in the water-in-crude oil microemulsion at the fluid-fluid interface. According to previous studies [33,35], the controlling mechanism is associated with two coalescence-suppressing interfacial barriers between fluids. Summarizing the IFT response, higher values of IFT at the interface will enhance the interfacial viscoelastic properties, which, in turn, is expected to produce bigger oil drops. 
Table 7. Interfacial tension (IFT) between brines and crude oil at $22{ }^{\circ} \mathrm{C}$.

\begin{tabular}{ccc}
\hline Nr. & Brines & IFT $(\mathbf{m N} / \mathbf{m})$ \\
\hline 1 & SSW & 2.2 \\
2 & $\mathrm{SSW}+\mathrm{SO}_{4}{ }^{2-}$ & 4.47 \\
3 & $\mathrm{SSW}^{2-} \mathrm{SO}_{4}{ }^{2-}$ & 2.06 \\
4 & $\mathrm{DSSW}$ & 9.4 \\
\hline
\end{tabular}

\subsubsection{IFV Results}

Figure 5 shows the measured oil drop volume in $\mathrm{SSW}+2 \mathrm{SO}_{4}{ }^{2-}$ brine, where oil drop sustained to the needle for $43 \mathrm{~min}$ before snap-off, resulting in $12.5 \mu \mathrm{L}$ oil volume. Similarly, oil drop volume and snap-off time is measured for three more brines, as presented in Table 8.
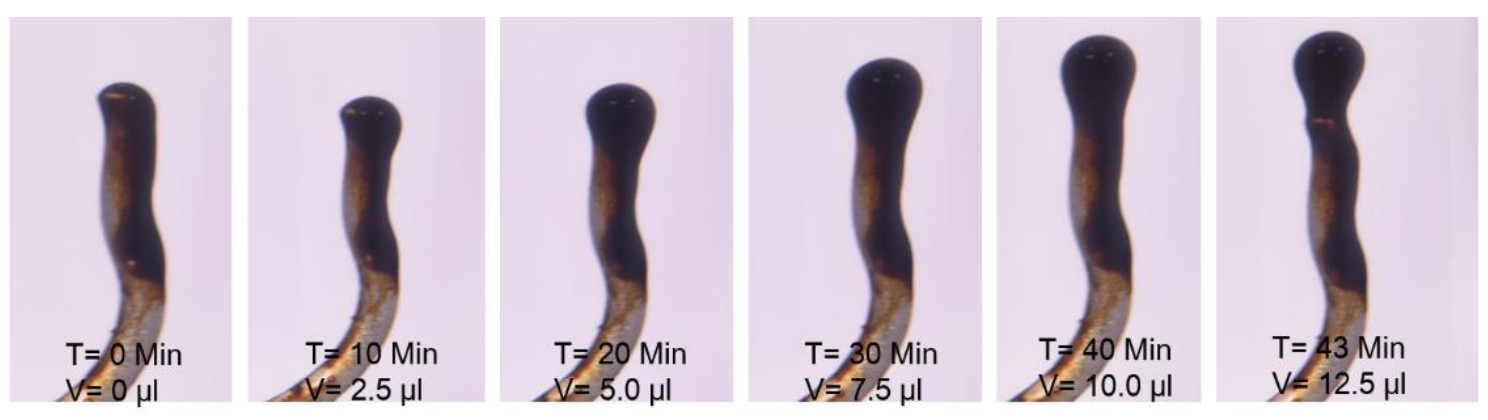

Figure 5. Oil-drop volume increase until snap-off point in $\mathrm{SSW}+2 \mathrm{SO}_{4}{ }^{2-}$ brine (Indirect interfacial viscoelastic response).

Table 8. Oil-drop size analysis before snap-off.

\begin{tabular}{ccc}
\hline Brine & Time Till Snap-Off & Oil-Drop Size \\
\hline & Minutes & $\mu \mathrm{L}$ \\
\hline $\mathrm{SSW}$ & 21 & 7.5 \\
$\mathrm{SSW}+4 \mathrm{SO}_{4}{ }^{2-}$ & 11 & 5.0 \\
$\mathrm{SSW}+2 \mathrm{SO}_{4}{ }^{2-}$ & 43 & 12.5 \\
$\mathrm{DSSW}$ & 48 & 12.5 \\
\hline
\end{tabular}

The interfacial viscoelastic response of fluids appears to be in line with the results of IFT measurements. As IFT data depicted the lowest value for $\mathrm{SSW}+4 \mathrm{SO}_{4}{ }^{2-}$ brine, the smallest drop size is expected for this brine. A small drop volume is produced, due to water-in-crude oil micro emulsion at the fluid-fluid interface (coalescence-suppressing interfacial barriers), which resulted in the quick oil drop snap-off from the needle. Moreover, $\mathrm{SSW}+2 \mathrm{SO}_{4}{ }^{2-}$ resulted in two times the IFT compared to SSW; presumably, this is due to the generated viscoelastic layer (at the interface), because of sulfate in brine and polar compounds in the oil. The higher IFT value generated a bigger oil drop of $12.5 \mu \mathrm{L}$. Note that, bigger oil drop of $12.5 \mu \mathrm{L}$ size is also produced in DSSW.

Overall, it is observed that a slightly higher IFT is the indication of an improved interfacial viscoelastic layer developed at the oil-brine interface. This improved IFV will assist the continuous oil flow resulting bigger oil drop (ganglia) during brine flood, and hence is expected to recover more oil.

\subsubsection{Wettability Conditions of Micromodels}

Wettability of the micromodel was confirmed by visual observation, through the concave/convex interface of the reservoir fluids (oil and brine) with a circular matrix structure. The concave shape of the wetting phase spreading over the rock matrix can be seen in Figure 6 with oil initialization. However, the non-wetting phase adopted the convex shape at the fluid interface. The water-wet micromodel 
had the concave shape of the water phase (in blue) and the convex shape of the oil phase (in green). Similarly, the oil-wet micromodel had the concave shape of the oil phase (in green) and the convex shape of the water phase (in blue). For the complex-wet micromodel, some parts were water-wet while other parts were oil-wet.
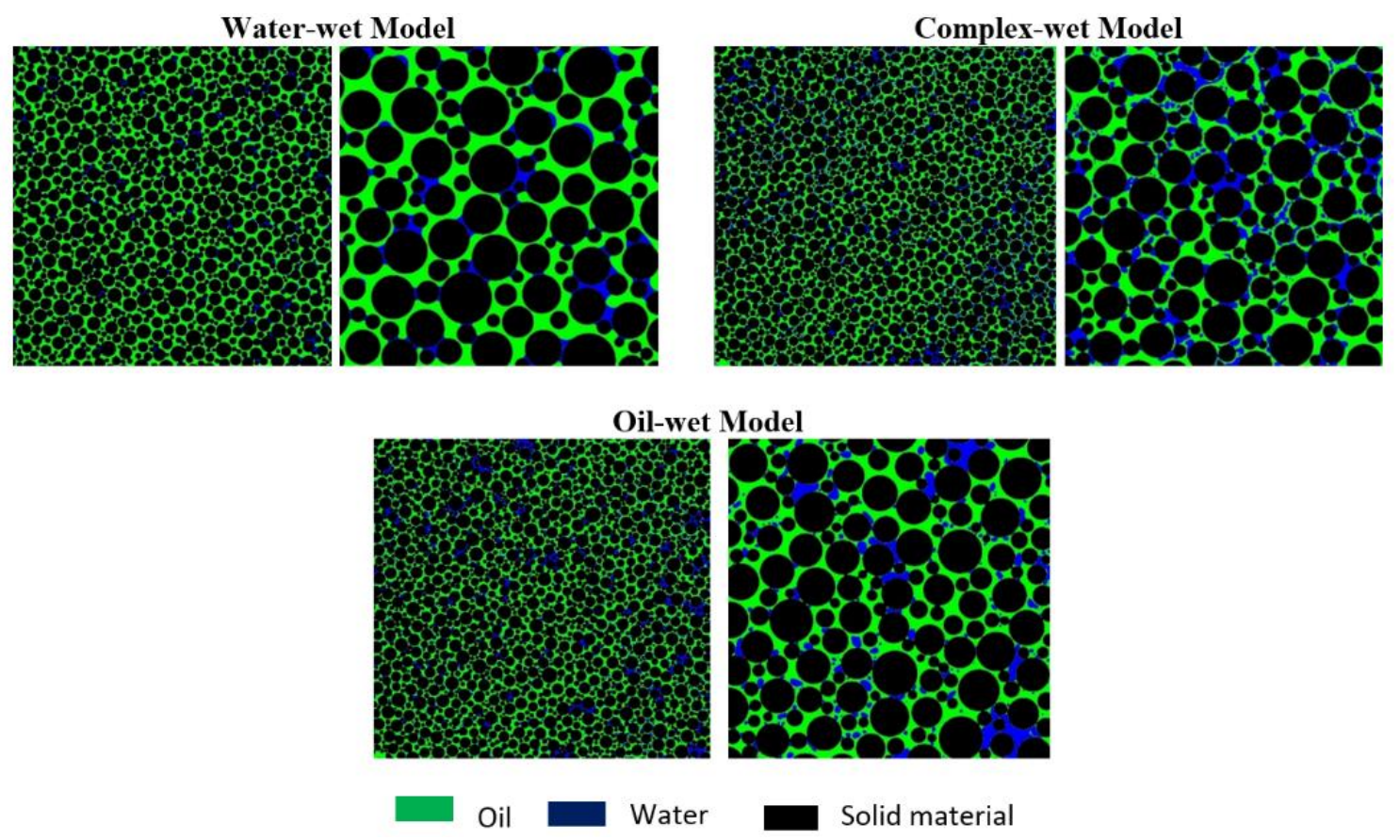

Figure 6. Micromodel with different wettability conditions. Left:each wettability condition represents the micromodel; right zoomed image of the bottom right corner for each micromodel.

\subsection{Microfluidics-Oil Recovery and Pressure Response for Secondary Mode Brine Flood}

\subsubsection{Oil-Wet Artificial Model}

SSW injection was performed as the base case, and SSW flooding was repeated in the cleaned model to observe the reproducibility of the oil recovery data. From Figure 7, the main flooding was a straight flow path between the injection and production points. Figure 8 shows oil recovery and pressure data for SSW flooding. Looking at the pressure response and final RFs, similar values are observed for both experiments. For further investigation into the effect of brine composition on oil recovery, three injection brines of Table 2 were flooded in the secondary mode. Figure 9 describes RF profiles and pressure responses for the four injection brines. Table 9 summarizes further details with regards to additional oil recovery with modified brines flooding (compared to the SSW injection).

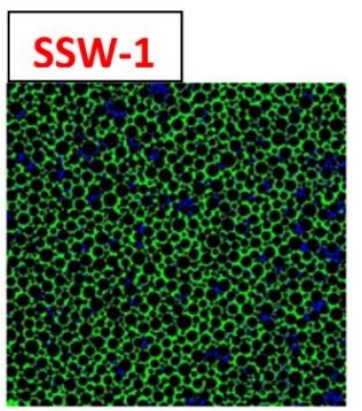

Oil

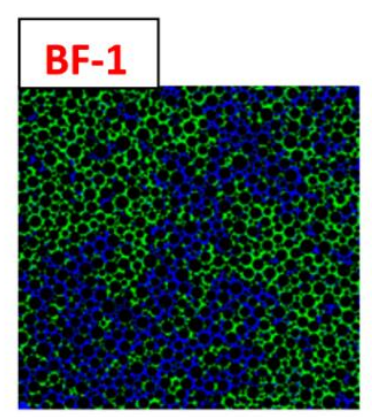

Water

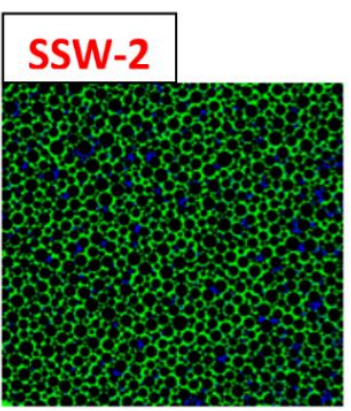

Solid material

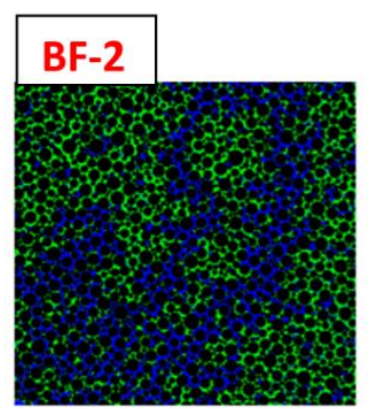

Figure 7. Artificial structure oil-wet micromodels used for synthetic seawater (SSW) flooding. SSW-1/SSW-2 represents the oil initialization, while BF-1/BF-2 represents after 10 PV injected brine. 

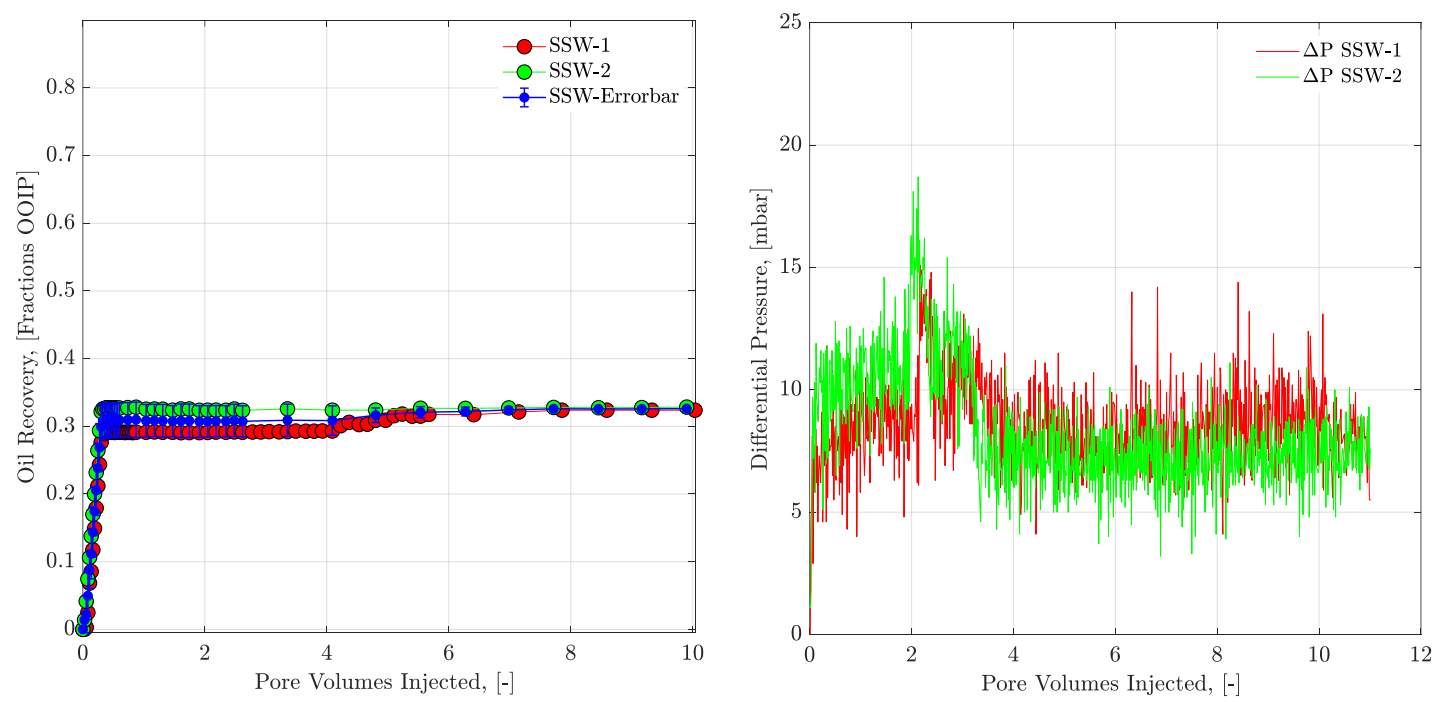

Figure 8. Oil recovery and pressure drop versus PV injected for artificial structure oil-wet micromodel. SSW injection is performed as the secondary mode for both flooding experiments.
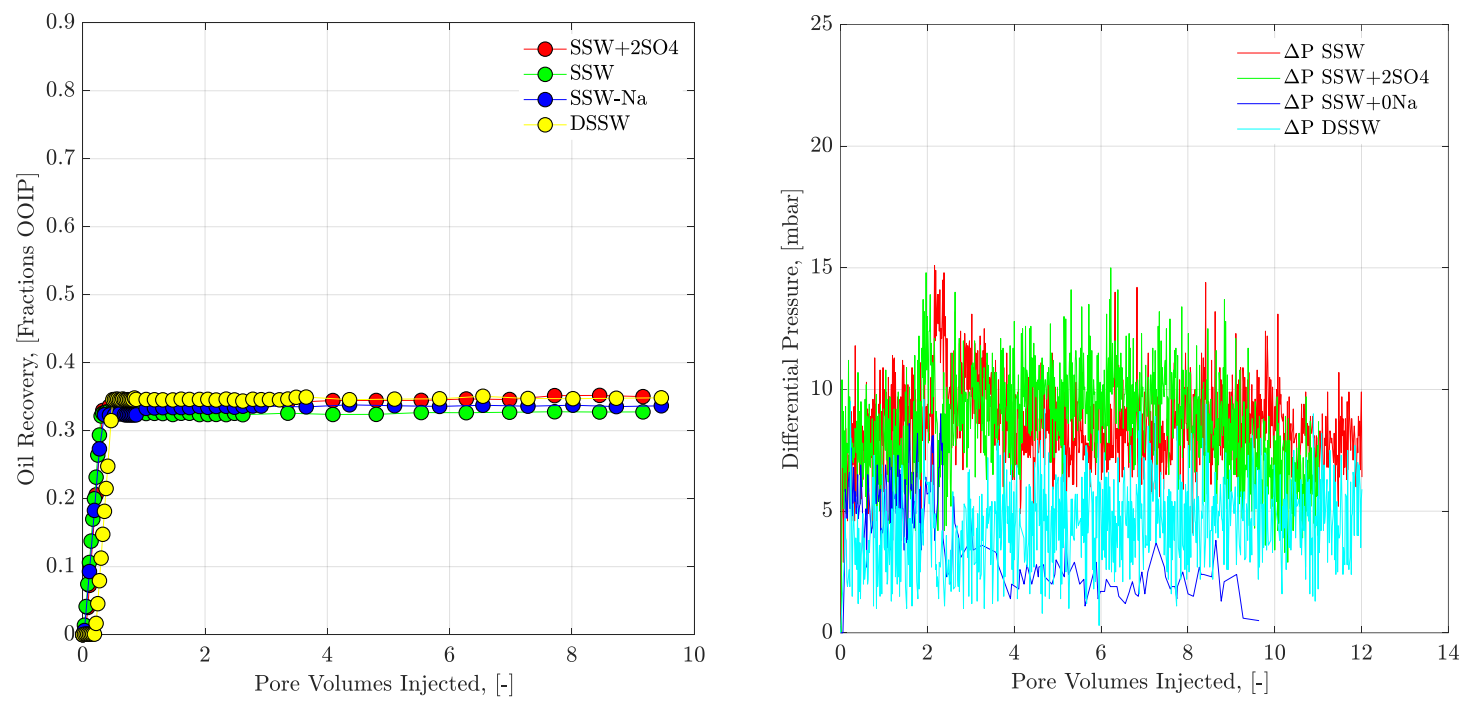

Figure 9. Oil recovery and pressure drop versus PV injected for artificial structure oil-wet micromodel. Four injection brines of Table 2 are flooded as the secondary mode.

Table 9. Summary of artificial structure oil-wet micromodel with initial oil saturation, connate water saturation and final oil recovery factor.

\begin{tabular}{cccccc}
\hline \multirow{2}{*}{ Experiment } & \multirow{2}{*}{ Flooding Brine } & Soi & Swc & RF & Additional RF \\
\cline { 3 - 6 } & & & & $\mathbf{( \% )}$ & \\
\hline 1 & SSW & 85.02 & 14.98 & 32.84 & - \\
2 & SSW & 83.44 & 16.56 & 32.38 & - \\
3 & ${\text { SSW }+2 \mathrm{SO}_{4}{ }^{2-}}$ & 85.13 & 14.87 & 35.01 & 2.63 \\
4 & SSW-Na & 85.64 & 14.36 & 33.66 & 1.27 \\
5 & DSSW & 83.48 & 16.52 & 34.84 & 2.46 \\
\hline
\end{tabular}

The slightly higher additional oil recovery from brine (3-5 from Table 9) flooding, compared to SSW injection was due to the fluid-fluid interfacial interaction developed between the oil and brine. The main reason for this could be a negligible local wettability alteration (rock-fluid interaction) of the micromodel established by injected brines. Sulfate-modified water and DSSW do not show a 
strong ability to disturb the hydrophobic layer coated on the matrix of the micromodel for wettability alteration. It is believed that this additional oil recovery was obtained due to the improved ionic interfacial response at the interface (fluid-fluid interaction). This ionic interfacial interaction developed due to a slight increase in the static IFT at the interface between the modified brines and the oleic phase. Further, the concept of PDI/non-PDI ions for SSW-Na brine flood did not work as expected, and produced only $1.27 \%$ additional oil. Hence, this indicates that adding/removing the PDI/non-PDI ions works, focusing on the concept of wettability alteration as a main recovery mechanism. Considering the economic aspect of the project, sulfate-modified $\left(\mathrm{SSW}+2 \mathrm{SO}_{4}{ }^{2-}\right)$ injection was found to be a suitable brine when comparing the extra oil recovery and brine preparation (the removal of $\mathrm{NaCl}$ from SSW or dilution of the SSW).

Figure 10 is the final image after $\approx 10$ PV brine flood (Table 9 injection brine). Table 9 describes the initial oil saturation and connate water saturation, which fall in the same range. RF represents the final RF after 10 PV injected. Further, additional oil RF represents the additional oil produced after brine flood compared to SSW. Looking at the flooded flow paths of Figure 10, it is clear that two brines $\left(\mathrm{SSW}+2 \mathrm{SO}_{4}{ }^{2-}\right.$ and DSSW) swept slightly better than the other two brines. The reason is the previously discussed improved fluid-fluid interfacial interaction.

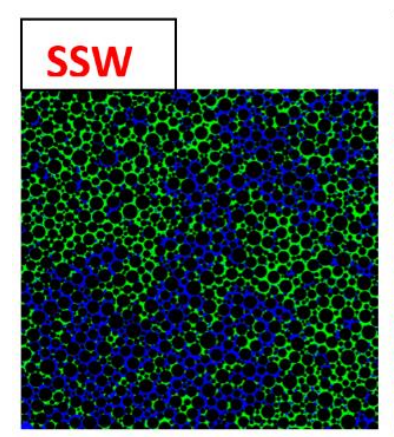

Oil

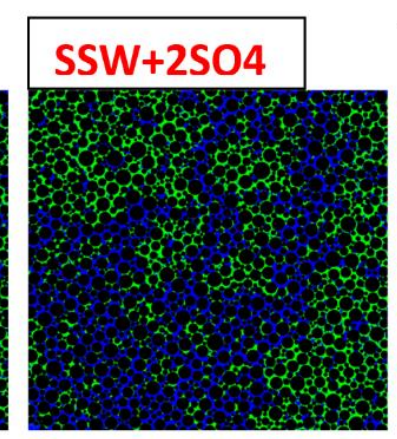

Water
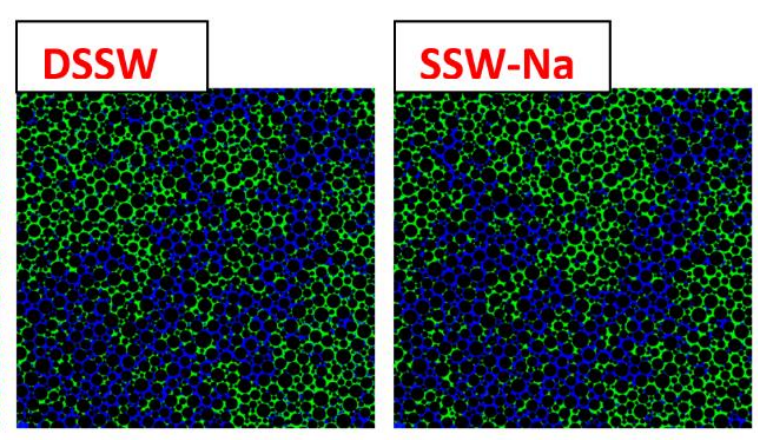

Solid material

Figure 10. Artificial structure oil-wet micromodels used for injection brines mentioned in Table 2. Figures represent the oil recovery after 10PV injected brine.

\subsubsection{Mixed/Complex-Wet Artificial Model}

As previously mentioned, a model with the same characteristics as the oil-wet model and pore geometry was used. Some parts of this model were oil-wet while others were water-wet, leading to its name- a complex-wet model. Three injection brines of Table 2 were flooded at injection flux of $1.0 \mathrm{ft} /$ day to compare the RFs. For reproducibility of the results, a modified water $\left(\mathrm{SSW}+2 \mathrm{SO}_{4}{ }^{2-}\right.$ ) injection was repeated to observe the RFs, as displayed in Figure 11.

Almost the same final oil RF and pressure responses were measured for both experiments, confirming reproducibility of the data. For further investigation, $\mathrm{SSW}+2 \mathrm{SO}_{4}{ }^{2-}$ and SSW-Na brines were injected through this model, to compare the RFs presented in Figure 12.

Both brines (SSW $+2 \mathrm{SO}_{4}{ }^{2-}$, SSW-Na) produced higher recovery compared to SSW injection (see Table 10). Again, the mechanism behind the increased production is the higher ionic interaction at the brine-oil interface compared to SSW. Furthermore, the wettability alteration mechanism (rock-fluid interaction) is not strong enough to produce additional oil, compared to core flooding. Moreover, the pressure profile for the complex-wet model was the same as for the oil-wet model for all brines except SSW-Na. Figure 13 shows the flooding patterns for fluids after 10 PV brine injection. 

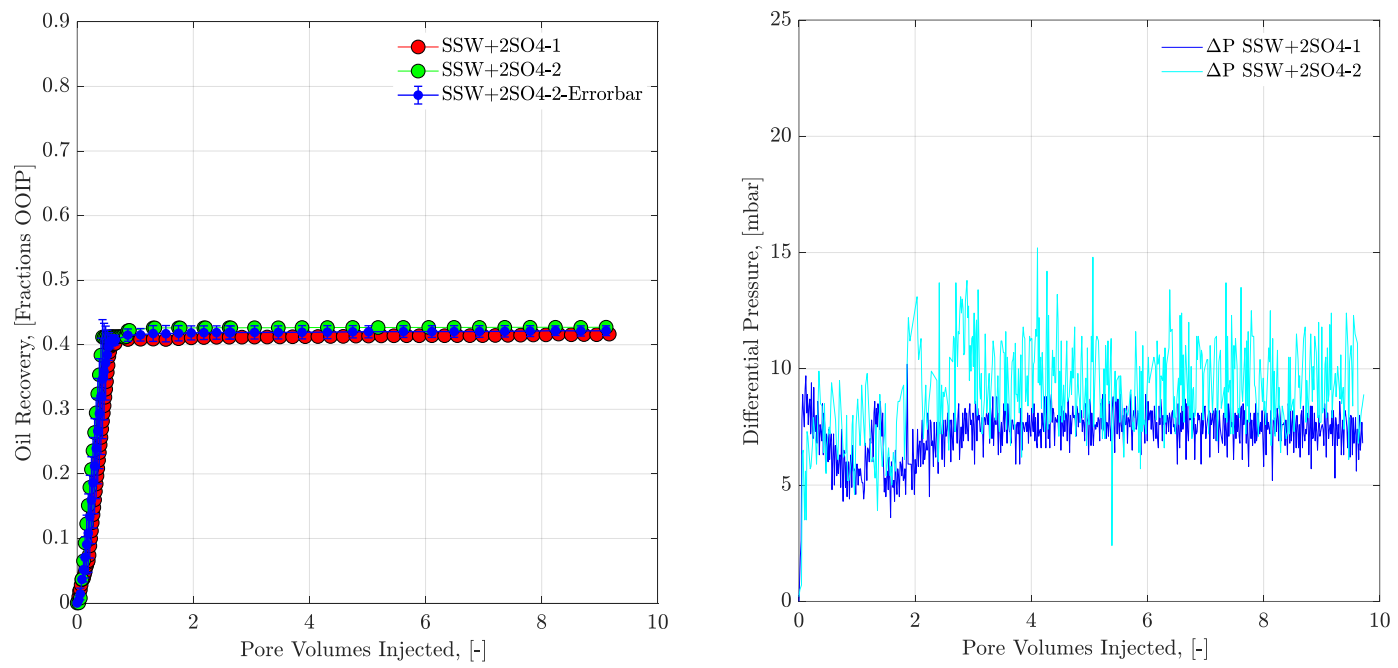

Figure 11. Oil recovery and pressure drop versus PV injected for artificial structure complex-wet micromodel. $\mathrm{SSW}+2 \mathrm{SO}_{4}{ }^{2-}$ injection is performed as the secondary mode for both flooding experiments.
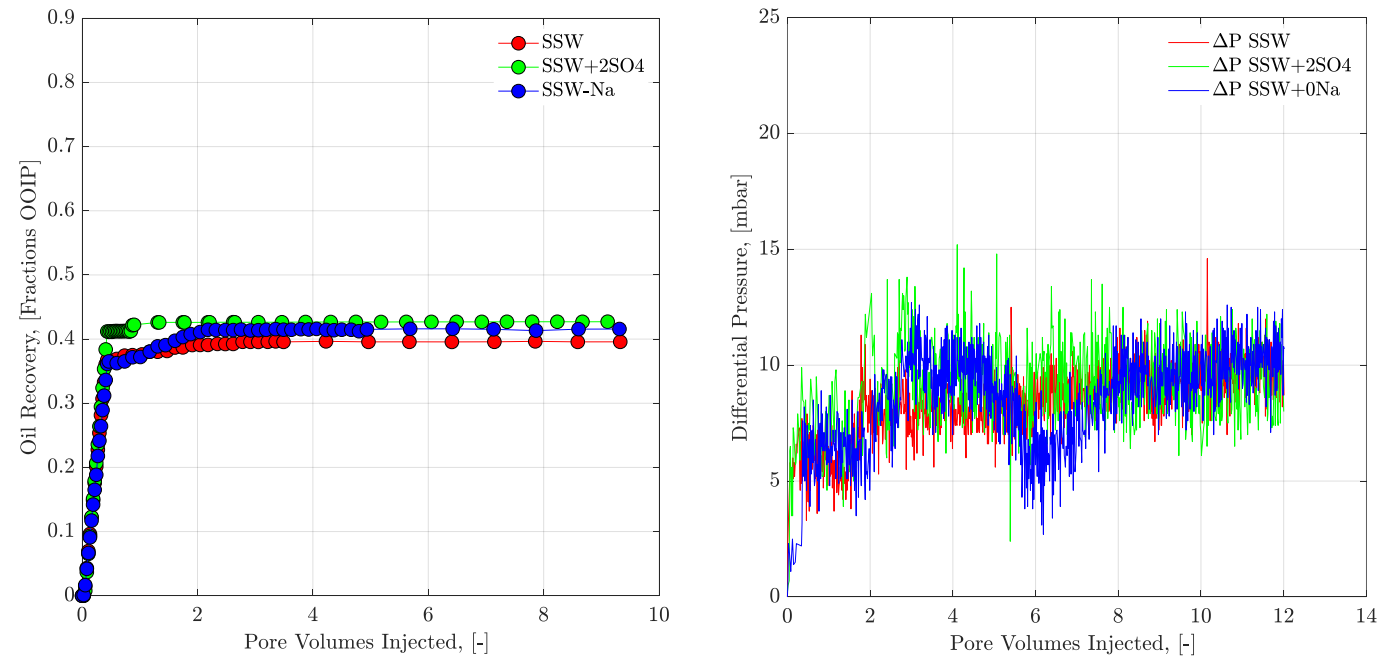

Figure 12. Oil recovery and pressure drop versus PV injected for artificial structure complex-wet micromodel. Three injection brines of Table 2 are flooded as the secondary mode.

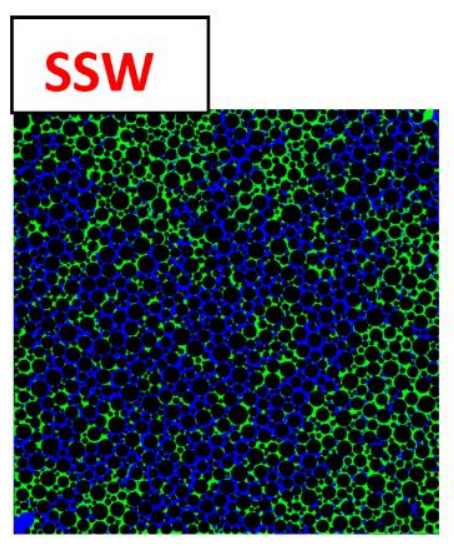

Oil

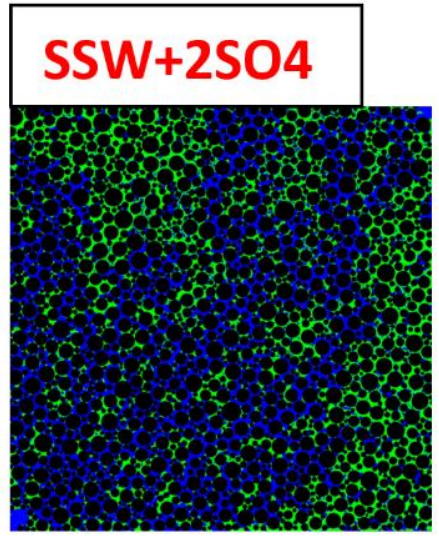

Water

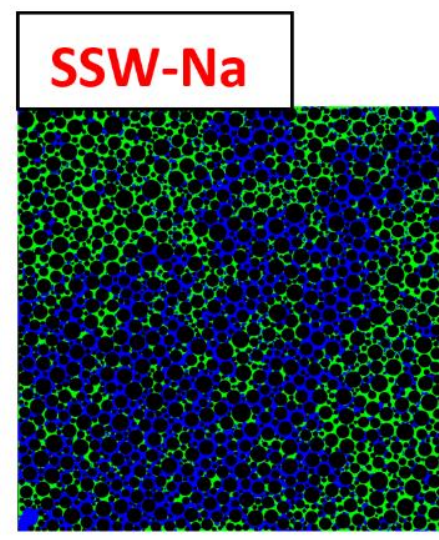

Solid material

Figure 13. Artificial structure complex-wet micromodels used for three injection brines mentioned in Table 2. Figure represents the oil recovery after 10PV injected brine. 
Table 10. Summary of artificial structure complex-wet micromodel with initial oil saturation, connate water saturation and final oil recovery factors.

\begin{tabular}{cccccc}
\hline \multirow{2}{*}{ Experiment } & \multirow{2}{*}{ Flooding Brine } & Soi & Swc & RF & Additional RF \\
\cline { 3 - 6 } & & & & $\mathbf{( \% )}$ & \\
\hline 1 & SSW & 81.28 & 18.73 & 39.58 & - \\
2 & ${\text { SSW }+2 S_{4}}_{3}$ & 80.66 & 19.34 & 42.71 & 3.13 \\
3 & SSW-Na & 76.40 & 23.60 & 41.55 & 1.97 \\
\hline
\end{tabular}

\subsubsection{Water-Wet Artificial Model}

SSW injection showed the reproducibility of the results in the water-wet micromodel, as shown in Figure 14. Furthermore, water-wet micromodel experiments showed slightly higher oil recovery from SSW flooding, compared to SSW $+2 \mathrm{SO}_{4}{ }^{2-}$ injection, as shown in Figure 15. As described earlier, $\mathrm{SSW}+2 \mathrm{SO}_{4}{ }^{2-}$ works effectively if the reservoir is oil-wet or mixed-wet. This approach was confirmed during the micromodel experimental investigation. Furthermore, it can be seen that pressure response is almost half that of the pressure profiles of both previously discussed systems, as can be seen in Figure 15. The negative additional RF in Table 11 represents lower oil recovery through $\mathrm{SSW}+2 \mathrm{SO}_{4}{ }^{2-}$ flooding compared to SSW. Figure 15 shows the recovery profiles and pressure responses of both injected brines for water-wet micromodels. Further, Figure 16 represents the flooding pattern after $10 \mathrm{PV}$ of both brine flooding.

Table 11. Summary of artificial structure water-wet micromodel with initial oil saturation, which connate water saturation and final oil recovery factors.

\begin{tabular}{cccccc}
\hline \multirow{2}{*}{ Experiment } & \multirow{2}{*}{ Flooding Brine } & Soi & Swc & RF & Additional RF \\
\cline { 3 - 6 } & & & & $\mathbf{( \% )}$ & \\
\hline 1 & $\mathrm{SSW}$ & 93.19 & 6.82 & 53.77 & - \\
2 & $\mathrm{SSW}_{2} \mathrm{SO}_{4}$ & 92.74 & 7.26 & 52.85 & -0.92 \\
\hline
\end{tabular}
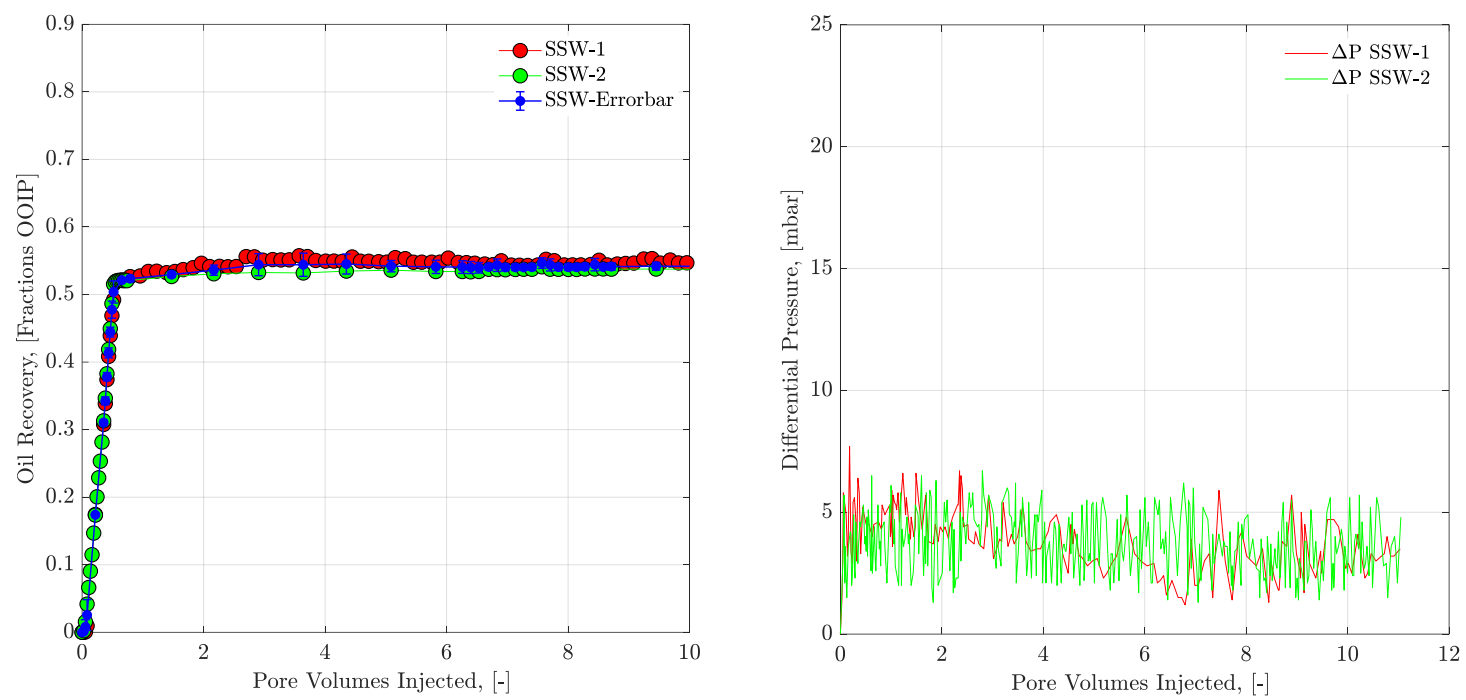

Figure 14. Oil recovery and pressure drop versus PV injected for water-wet artificial structure micromodel. SSW injection is performed as the secondary mode for both flooding experiments. 

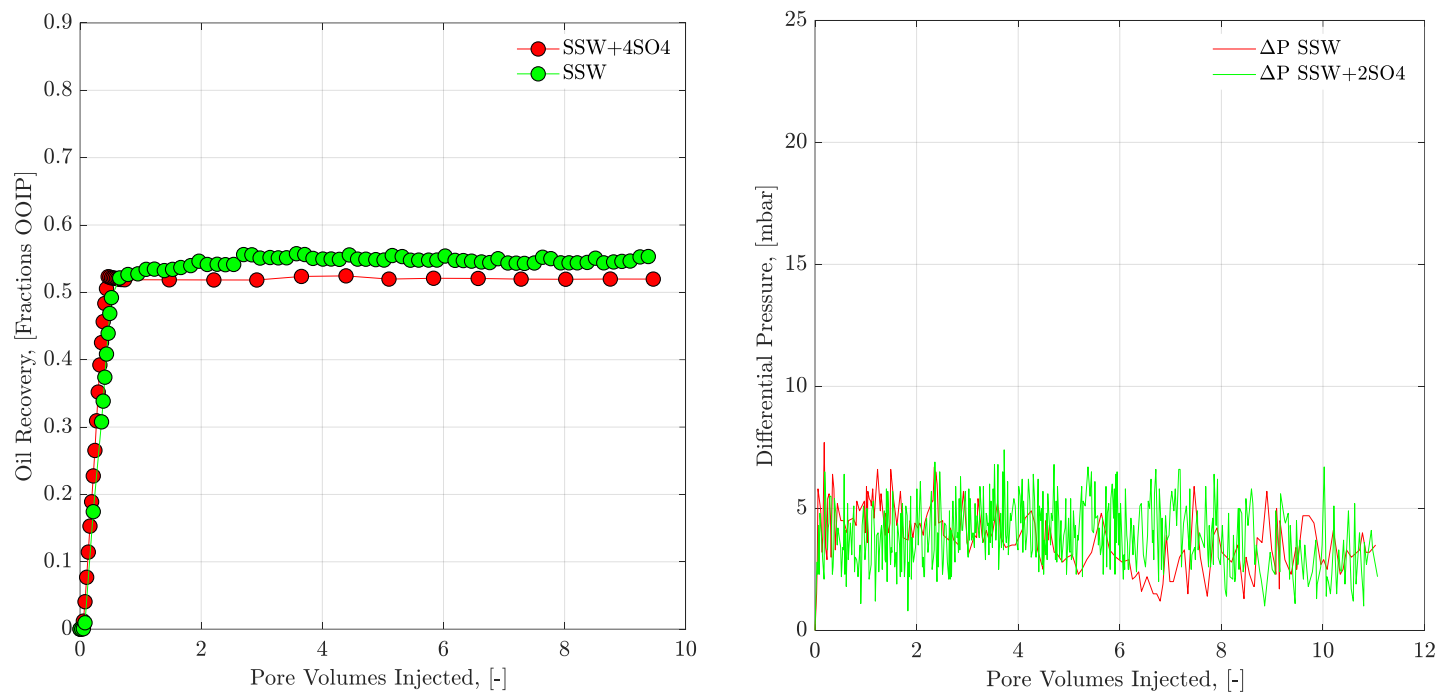

Figure 15. Oil recovery and pressure drop versus PV injected for water-wet artificial structure micromodel. Two injection brines of Table 2 are flooded as the secondary mode.
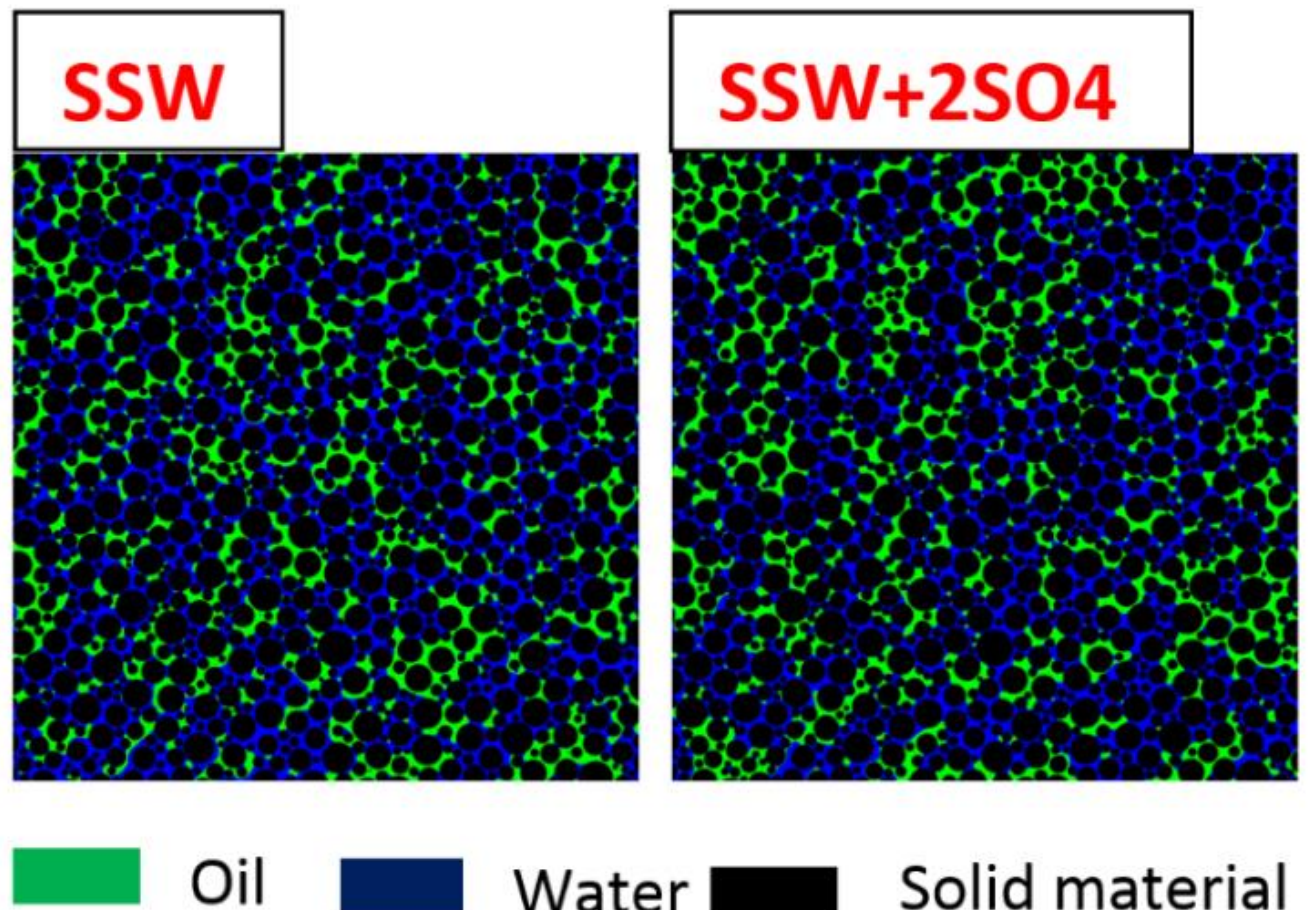

\section{Water}

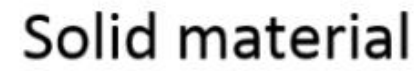

Figure 16. Real structure water-wet micromodels used for two injection brines mentioned in Table 2. Figure represents the oil recovery after 10PV injected brine.

\subsubsection{Water-Wet Real Structure Model}

Three brine floods were performed as mentioned in Table 12 and described in Figure 17. The final $\mathrm{RFs}$ were similar for SSW and SSW+2SO ${ }_{4}{ }^{2-}$. The results are in line with the oil recovery results of the artificial structure water-wet micromodel discussed. Furthermore, DSSW produced slightly less oil $(0.58 \%)$, compared to the other two brines. This small difference in oil recovery may be due to experimental artefacts, and can considered to be the same oil recovery. This analysis justifies that oil-wet or complex-wet porous media systems are important for producing extra oil with sulfate-modified seawater or low saltwater. Figure 17 explains that $\mathrm{SSW}+2 \mathrm{SO}_{4}{ }^{2-}$ produces the maximum oil at breakthrough. Furthermore, DSSW requires higher injected PV to achieve oil recovery close to the 
other two brines. Compared to the micromodel discussed in the previous section (water-wet artificial model), the difference between oil recovery was less than $1 \%$ for both models for SSW and SSW+2SO ${ }_{4}^{2-}$ flooding. This comparison emphasizes the hypothesis that sulfate-modified water flooding in the water-wet system will not work efficiently, and that produced brine/SSW is favorable to perform secondary-mode brine flooding. Figure 18 shows the oil initialization condition and after 10 PV brine flood for three brines. Comparing the final RFs to the RFs of all previous experiments, the artificial structure water-wet model is closer. This comparison further justifies that under the same wetting conditions, brine could recover oil within a margin of $3 \%$. This difference increased to $22 \%$ by changing the wettability of the system (oil-wet model).
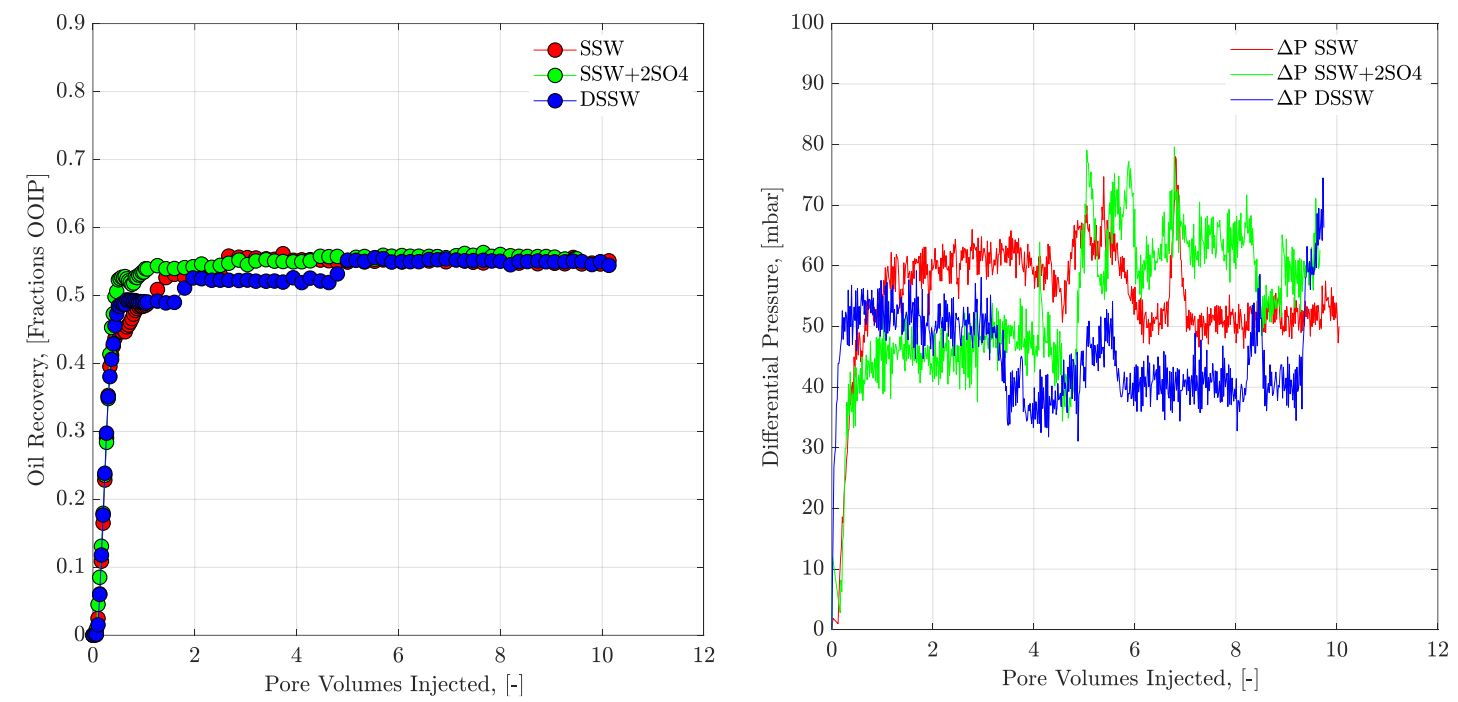

Figure 17. Oil recovery and pressure drop versus PV injected for water-wet real structure micromodel. Three injection brines of Table 2 are flooded as the secondary mode.
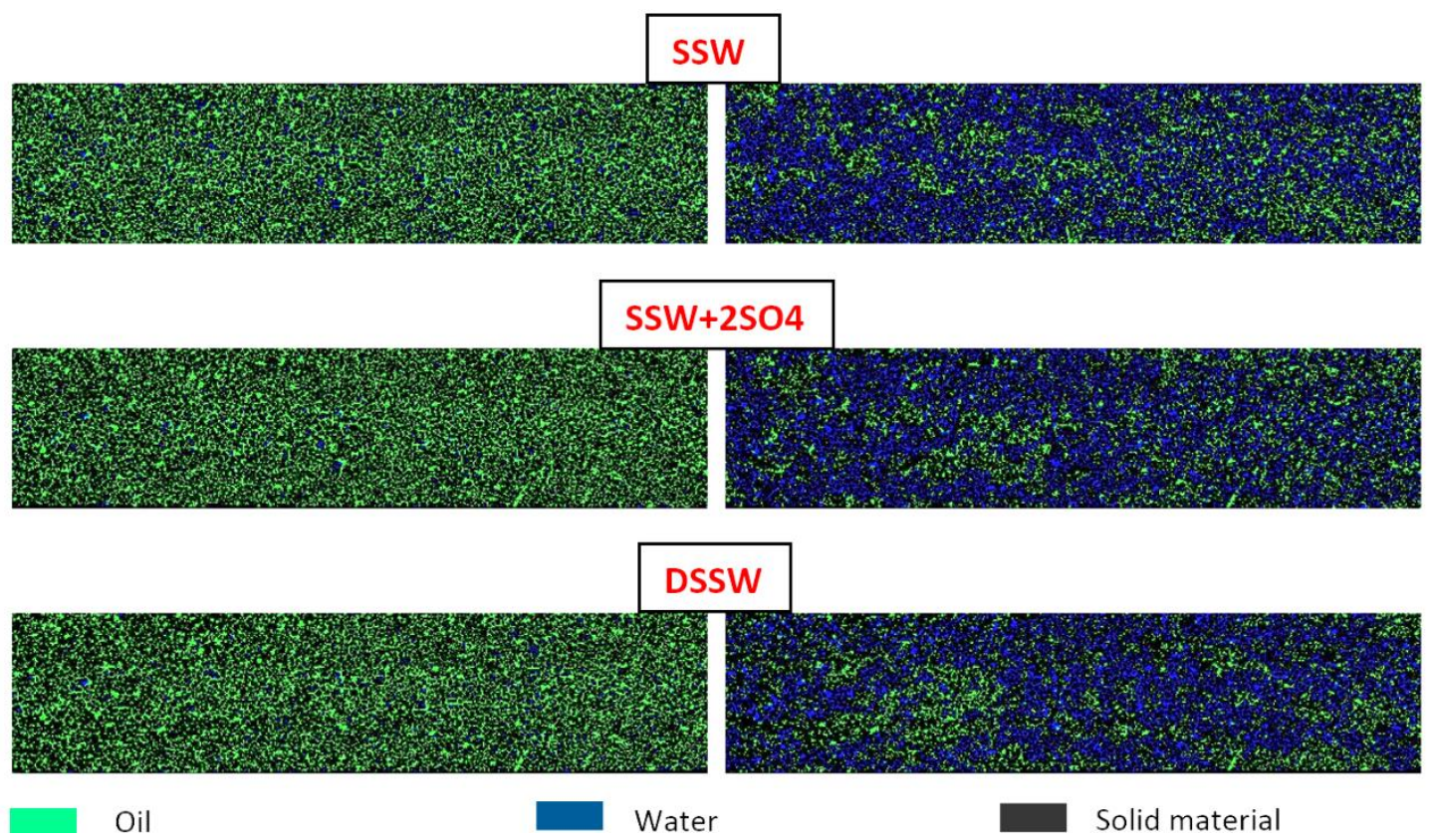

Figure 18. Real-structure water-wet micromodels used for three injection brines mentioned in Table 2. Figures on the left side represent the oil initialization; while on the right side represent the oil recovery after 10 PV brines flooded. 
Table 12. Summary of real structure water-wet micromodel with initial oil saturation, connate water saturation and final oil recovery factors.

\begin{tabular}{cccccc}
\hline \multirow{2}{*}{ Experiment } & \multirow{2}{*}{ Flooding Brine } & Soi & Swc & RF & Additional RF \\
\cline { 3 - 6 } & & & & $\mathbf{( \% )}$ & \\
\hline 1 & SSW & 91.15 & 8.85 & 55.01 & - \\
2 & ${\text { SSW }+2 \mathrm{SO}_{4}}$ & 96.49 & 3.51 & 55.40 & 0.39 \\
3 & $\mathrm{DSSW}$ & 95.32 & 4.68 & 54.43 & -0.58 \\
\hline
\end{tabular}

\subsection{Polymer Flood-Oil Recovery and Pressure Response for Tertiary Mode Polymer Flood}

\subsubsection{Polymer Viscosity Half the Oil Viscosity in Complex-Wet Model}

As described earlier, a polymer (1000 ppm) with half the viscosity of the oil $(9.58 \mathrm{mPa} \cdot \mathrm{s})$ was injected in the tertiary mode to observe additional oil recovery. The micromodel with complex wettability was used for polymer flooding. First, the bump-rate injection at a rate five times higher than that of the brine flood was performed, to eliminate any possible capillary end effects. A minor amount of recovered oil and increased pressure response for the bump rate can be seen in Figure 19. The polymer flood results for the tertiary mode are also shown. Figure 19 shows that no additional oil was produced by polymer injection in either experiments. One reason for this could be that the polymer followed the pre-flushed path of the brine and could not contribute additional recovery, due to lower aqueous viscosity compared to the oil. Furthermore, the pressure of the polymer flood was lower compared to the bump rate in both experiments, as shown in Figure 19. This analysis supports the assertion that the lower pressure difference for polymer flooding was the reason for no additional recovered oil.
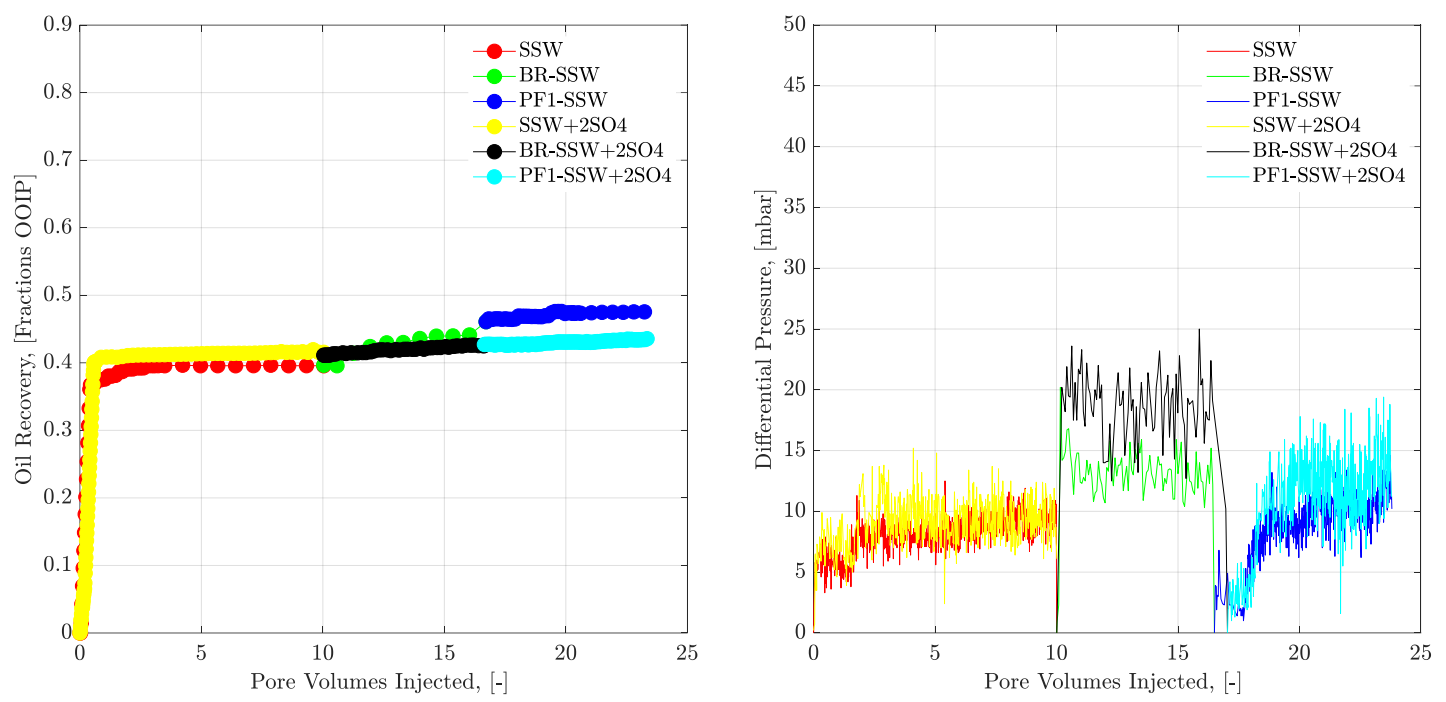

Figure 19. Oil recovery and pressure drop versus PV injected for complex-wet artificial structure micromodel. Polymer (half to the oil viscosity) flooding in tertiary mode after the brine flood in secondary mode.

\subsubsection{Polymer Viscosity Equal to the Oil Viscosity in Complex-Wet Model}

As a further step, the impact of increased polymer viscosity (equal to the oil viscosity) on oil recovery was investigated. To do so, 1500-ppm polymer was injected through the micromodels described in the previous sections. Figures 20 and 21 describe the additional oil recovered and the impact on pressure response. 

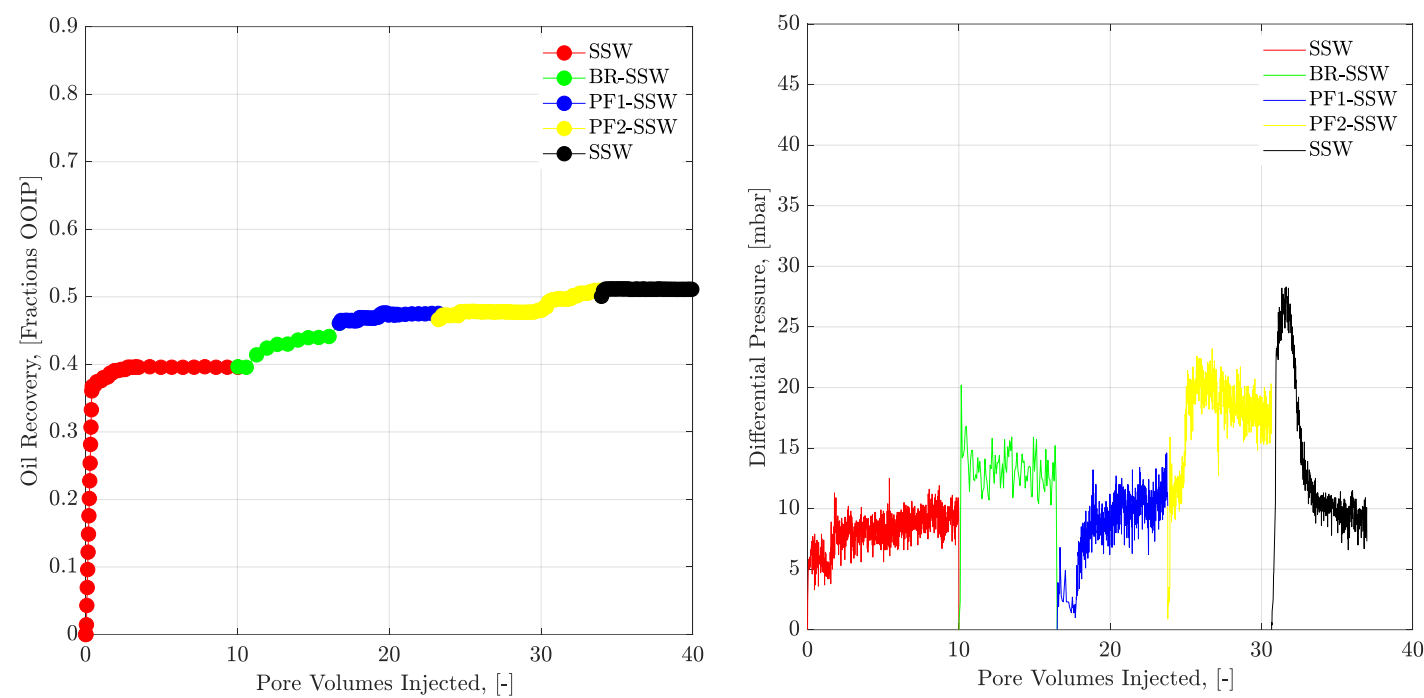

Figure 20. Oil recovery and pressure drop versus PV injected for complex-wet artificial structure micromodel. Polymer (equal to the oil viscosity) flooding in post-tertiary mode after the SSW brine flood in secondary mode.
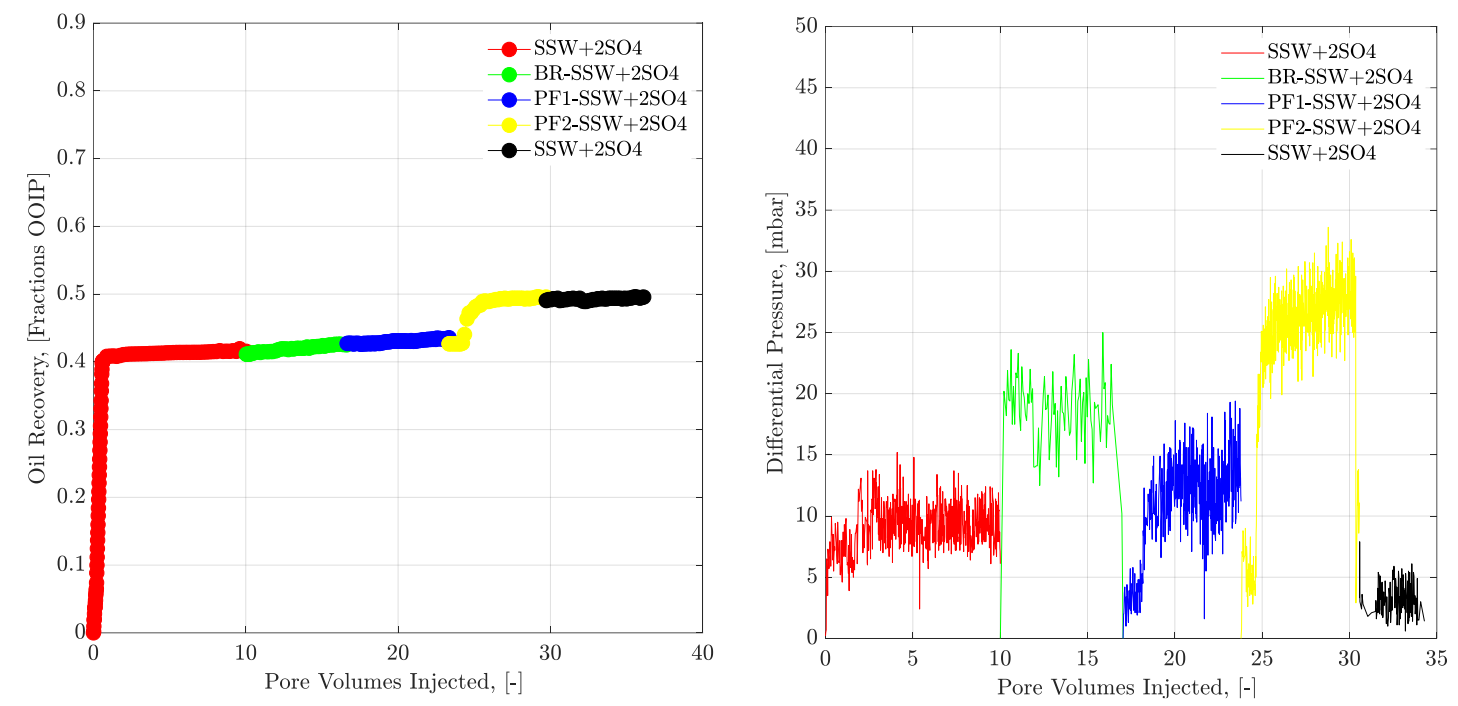

Figure 21. Oil recovery and pressure drop versus PV injected for the complex-wet artificial structure micromodel. Polymer (equal to the oil viscosity) flooding in post-tertiary mode after the $\mathrm{SSW}+2 \mathrm{SO}_{4}{ }^{2-}$ brine flood in secondary mode.

Polymer diluted in SSW resulted in additional oil recovery of 4.33\% (Figure 20), and the polymer prepared in $\mathrm{SSW}+2 \mathrm{SO}_{4}{ }^{2-}$ resulted in additional oil recovery of $6.91 \%$ (Figure 21). Overall recovery from both micromodels was approximately $50 \%$. Brine flooding was also performed after post-tertiary-mode polymer flooding, to observe further recovery due to any bypass flow through the micromodel, but, in both cases, no oil was recovered. The reason for this could be a loss of polymer viscosity, due to mechanical degradation while flowing through flow lines and the pump. This degradation caused a reduction in polymer viscosity, resulting in lower viscosity than that of the oil. Later, brine flooding was performed for the pre-flushed flow paths of polymer solutions, due to lower viscosity of the aqueous phase, compared to the viscosity of the trapped oil. This investigation and the comparison of its results with those outlined in the previous section suggest injecting polymer solution with a viscosity at least equal to the oleic phase in porous media. Lower polymer viscosity (half that oil) does not contribute to the economics of a polymer injection project. 


\subsubsection{Polymer Viscosity Equal to the Oil Viscosity in a Water-Wet Real Structure Model}

The same polymers described in Section 3.3.2 were injected through the real structure model.

The results are presented in Figure 22. Polymer flooding was performed after bump rate injection at a rate five times that of brine injection. Looking at the oil production profiles, the bump rate after SSW $+2 \mathrm{SO}_{4}{ }^{2-}$ produced more oil compared to SSW flooding. This could be due to detached and trapped oil drops in porous media, which are produced through high-pressure support of the bump rate. However, the polymer solution diluted in $\mathrm{SSW}+2 \mathrm{SO}_{4}{ }^{2-}$ produced $2.61 \%$ additional oil recovery after the bump rate, and the polymer prepared in SSW produced $1.69 \%$ additional recovery. This marginal 1\% difference in oil recovery was due to the increase in pressure across the model, as can be seen in Figure 22. This rapid increase in pressure was caused by microgel plugging the flow channels. Furthermore, comparing the results of the same polymer flood in the artificial structure model shows that this model produced more recovery with polymer flooding. This higher oil recovery could be due to the wettability difference between the systems. Polymer flooding in the complex-wet micromodel was more efficient than in the water-wet micromodel. Brine injection helped to develop the fluid-fluid interaction and the follow-up higher viscosity aqueous phase efficiently sweep the detached oil, resulting in a higher recovery.
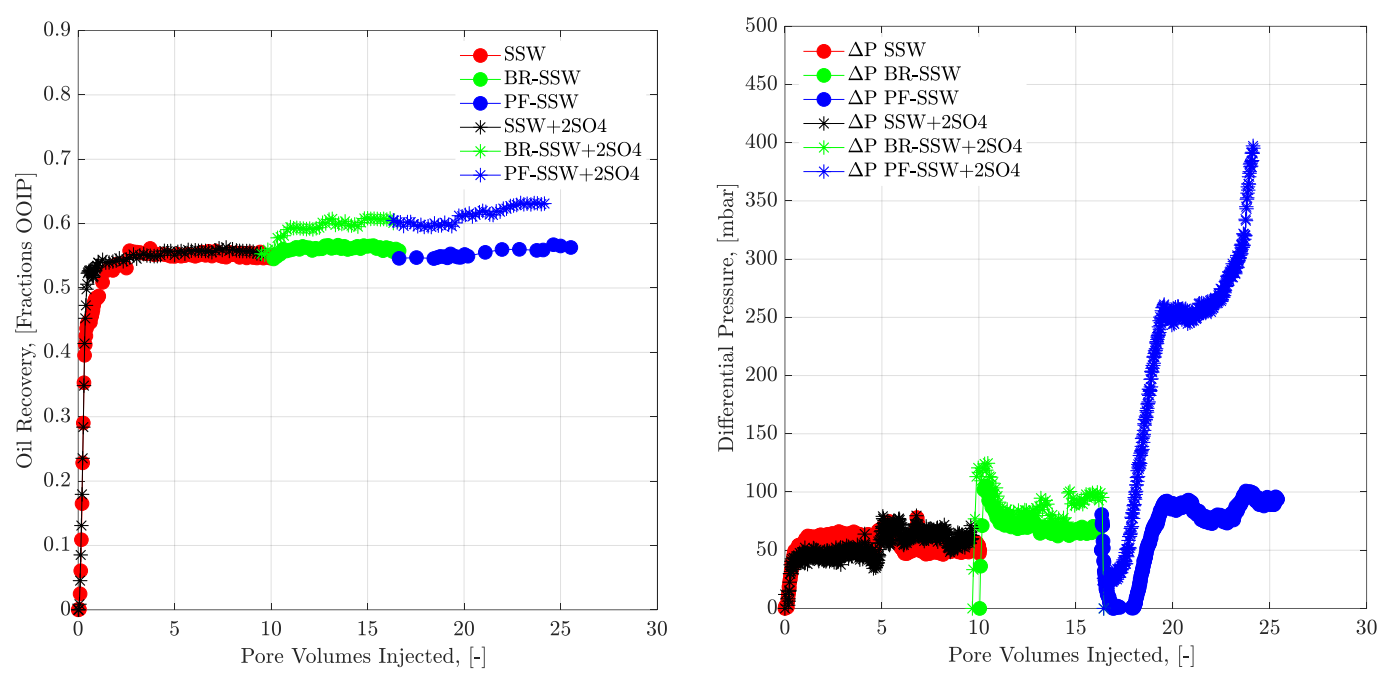

Figure 22. Oil recovery and pressure drop versus PV injected for water-wet real structure micromodel. Polymer (equal to the oil viscosity) flooding in tertiary mode after the $\mathrm{SSW}+2 \mathrm{SO}_{4}{ }^{2-} / \mathrm{SSW}$ brine flood in secondary mode.

\subsection{Comparison of Micromodel Flood and Bentheimer Core Flood}

Comparisons of secondary mode brine floods in oil-wet artificial structure micromodel and Bentheimer core plugs are described in Figure 23. A detailed description of core flooding recovery mechanisms and pressure profiles are described in previous work [10]. In Figure 23, MM represents the recovery factors of micromodel, while CF represents the recovery factors of core flood and Difference represents the difference in recovery factors between both flooding. It is observed that brine flood of SSW and SSW-Na produced almost the same recovery factors (in CF and MM), with a difference of $1.89 \%$ for SSW and $0.37 \%$ for SSW-Na. The difference for SSW $+2 \mathrm{SO}_{4}{ }^{2-}$ is significant, with a $10.66 \%$ recovery factor. Sulfate-modified produced a higher oil recovery through core plugs as compared to the micromodel. As previously discussed, wettability alteration (rock-fluid interaction) and IFV (fluid-fluid interaction) are the main recovery mechanisms for effective sulfate-modified water. It is believed that the IFV concept only worked in micromodel, resulting in the additional recovery of $2.35 \%$. However, the wettability alteration did not happen, because of the strong adsorbed hydrophobic chemical layer at the matrix to make it oil-wet. Ionic activity because of sulfate-modified water is not strong enough to destroy the established oil-wet layer at the matrix. Furthermore, it is also believed 
that the mechanism of IFV in micromodel is not strong enough as compared to the mechanism in the core flood. The reason is the availability of multiple flow paths $\left(k_{x}, k_{y}, k_{z}\right)$ in the core plug for easier oil ganglia movement. While on the other hand, in the micromodel, there is restricted two-way permeability for fluid flow and limited to flow channels. Looking at the difference between SSW injection and $\mathrm{SSW}+2 \mathrm{SO}_{4}{ }^{2-}$, a higher oil recovery of $\mathrm{SSW}+2 \mathrm{SO}_{4}{ }^{2-}$ is observed for both approaches. Sulfate-modified water worked much better in the core plug compared to the micromodel, due to a strong rock-fluids interaction.

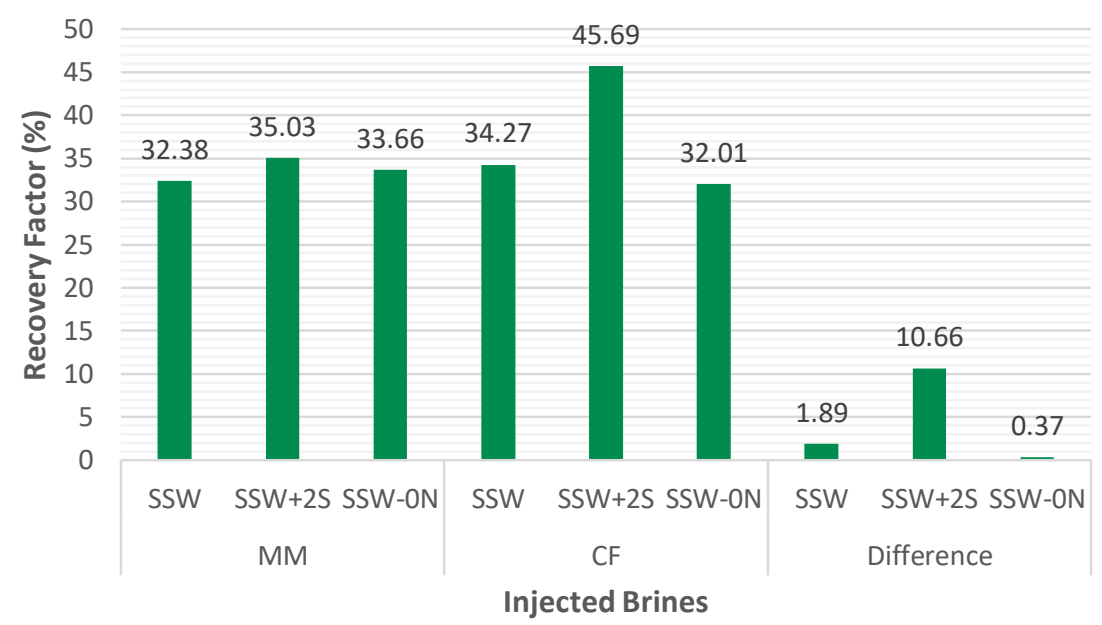

Figure 23. Comparison between oil-wet artificial structure micromodel and oil-wet Bentheimer core plugs recovery factors after brine flood in secondary mode.

Table 13 represents the overall comparison between both types of micromodels and the core flood experiments used for this study. As presented in Table 13, $\mathrm{SSW}+2 \mathrm{SO}_{4}{ }^{2-}$ produced higher oil recovery in oil-wet MM and CF, and in complex-wet MM. Further, we can also see that $\mathrm{SSW}+2 \mathrm{SO}_{4}{ }^{2-}$ could not produce extra oil, as compared to SSW flooding through both water-wet MM (artificial structure and real structure). This comparison justifies that an oil-wet or mixed-wet reservoir system is essential for fluid-fluid and rock-fluid interaction to contribute extra oil recovery. The oil recovery difference between SSW $+2 \mathrm{SO}_{4}{ }^{2-}$ and SSW flooding in oil-wet core plug is clear because of the strong rock-fluid interaction, which resulted in the local wettability alteration. Nevertheless, this rock-fluid interaction could not occur in micromodels, and difference in oil recovery between $\mathrm{SSW}+2 \mathrm{SO}_{4}{ }^{2-}$ and SSW flooding is smaller.

Table 13. Comparison of oil recoveries through both types of micromodels and core flood with different wettability. Recovery factors mentioned are only through secondary mode brines flood.

\begin{tabular}{|c|c|c|c|}
\hline \multirow{2}{*}{ Wettability } & \multirow{2}{*}{ Porous Media } & \multirow{2}{*}{ Injected Brine } & Recovery (\%) \\
\hline & & & Brine Flood \\
\hline \multirow{7}{*}{ Oil-wet } & \multirow{4}{*}{ Artificial structure } & SSW & 32.38 \\
\hline & & $\mathrm{SSW}+2 \mathrm{~S}$ & 35.03 \\
\hline & & SSW-0N & 33.66 \\
\hline & & DSSW & 34.84 \\
\hline & \multirow{3}{*}{ Core flood } & SSW & 34.27 \\
\hline & & $\mathrm{SSW}+2 \mathrm{~S}$ & 45.69 \\
\hline & & SSW-ON & 32.01 \\
\hline \multirow{3}{*}{ Complex-wet } & \multirow{3}{*}{ Artificial structure } & SSW & 39.58 \\
\hline & & $\mathrm{SSW}+2 \mathrm{~S}$ & 42.71 \\
\hline & & SSW-0N & 41.55 \\
\hline \multirow{5}{*}{ Water-wet } & \multirow{2}{*}{ Artificial structure } & SSW & 53.77 \\
\hline & & $\mathrm{SSW}+2 \mathrm{~S}$ & 52.85 \\
\hline & \multirow{3}{*}{ Real structure } & SSW & 55.01 \\
\hline & & $\mathrm{SSW}+2 \mathrm{~S}$ & 55.4 \\
\hline & & DSSW & 54.43 \\
\hline
\end{tabular}




\section{Conclusions}

Based on the experimental investigation and collected data outlined in this study, it can be concluded that the mechanisms of both wettability alteration and fluid interfacial interaction are of great importance for reducing the ROS. However, in the oil-wet micromodel, only the fluid-fluid interaction helped to produce the additional oil from $\mathrm{SSW}+2 \mathrm{SO}_{4}{ }^{2-}$. Additionally, there was no rock-fluid interaction in the oil-wet micromodel. One reason for this is that the oil-wet condition is achieved by applying a chemical layer adsorbed at the matrix structure, which is difficult to change to water-wet by modified water. The results also confirm that SSW $+2 \mathrm{SO}_{4}{ }^{2-}$, or low-salt water flooding, work efficiently only in oil-wet and complex-wet reservoir systems (for the conditions presented in this work). In a water-wet system, the fluid-fluid/rock-fluid interaction concept could not work in a promising manner.

Moreover, it was observed that polymer injection with a viscosity equal to that of oil can contribute to additional oil recovery through the micromodels. Polymer flooding after $\mathrm{SSW}+2 \mathrm{SO}_{4}{ }^{2-}$ contributed $2 \%$ higher recovery, compared to polymer injection after SSW, which is proposed as the appropriate combination of modified water flooding following polymer flooding. Subsequently, it was observed that the pore distribution and rock properties do not have a significant impact on oil recovery under the same wettability conditions (for the conditions presented in this work). Comparing the two types of water-wet models (artificial and real structure), nearly the same RF of 55\% through SSW flooding was achieved.

Author Contributions: M.T. performed experiments and defined methodology. R.E.H. worked on conceptualization and results validation, C.L.G. worked on the micromodels design and data comparison, S.S. performed micromodels chemical coating for wettability alteration and L.G. reviewed and performed editing. All authors have read and agreed to the published version of the manuscript.

Funding: This research received no external funding.

Acknowledgments: We acknowledge support by Open Access Publishing Fund of Clausthal University of Technology.

Conflicts of Interest: The authors declare no conflict of interest.

\section{Abbreviations}

$\begin{array}{ll}\text { BF } & \text { Brine flood } \\ \text { CF } & \text { Core flood } \\ \text { DSSW } & \text { Ten times diluted synthetic sear water } \\ \text { EOR } & \text { Enhanced oil recovery } \\ \text { FP } & \text { Flopaam 6035 S } \\ \text { LSF } & \text { Low salt flood } \\ \text { MM } & \text { Micromodel } \\ \frac{\eta_{p}}{\eta_{o}} & \text { Viscosity ratio between polymer to oil viscosities } \\ \text { SR } & \text { Shear Rate } \\ \text { SSW } & \text { Synthetic sea water } \\ \text { SW } & \text { Smart water } \\ \text { SWF } & \text { Smart water flood } \\ \text { TDS } & \text { Total dissolved solids } \\ \Delta P & \text { Pressure drop across the micromodel } \\ \text { PF } & \text { Polymer flood } \\ \text { ROS } & \text { Remaining Oil Saturation }\end{array}$

\section{References}

1. Morrow, N.R.; Valat, M.; Yidliz, H. Effect of Brine Composition on Recovery of an Alaskan Crude Oil by Waterflooding. Annu. Tech. Meet. 1996. [CrossRef]

2. Lager, A.; Webb, K.J.; Black, C.J.J.; Singleton, M.; Sorbie, K.S. Low salinity oil recovery-An experimental investigation. Petrophysics 2008, 49, 28-35. 
3. Morrow, N.R.; Tang, G.; Valat, M.; Xie, X. Prospects of improved oil recovery related to wettability and brine composition. J. Pet. Sci. Eng. 1998, 20, 267-276. [CrossRef]

4. Yft, S.; Lake, L.W.; Pope, G.A. A Coreflood Investigation of Low-Salinity Enhanced Oil Recovery. SPE Annu. Tech. Conf. Exhib. 2010. [CrossRef]

5. Tang, G.Q.; Morrow, N.R. Salinity, Temperature, Oil Composition, and Oil Recovery by Waterflooding. SPE Reserv. Eng. 1997, 12, 269-276. [CrossRef]

6. Winoto, W.; Loahardjo, N.; Xie, S.X.; Yin, P.; Morrow, N.R. Secondary and Tertiary Recovery of Crude Oil from Outcrop and Reservoir Rocks by Low Salinity Waterflooding. SPE Improv. Oil Recovery Symp. 2012. [CrossRef]

7. Xie, Q.; Ma, D.; Wu, J.; Liu, Q.; Jia, N.; Luo, M. Low Salinity Waterflooding in Low Permeability Sandstone: Coreflood Experiments and Interpretation by Thermodynamics and Simulation. SPE Asia Pac. Enhanc. Oil Recovery Conf. 2015. [CrossRef]

8. Zhang, Y.; Xie, X.; Morrow, N.R. Waterflood Performance by Injection of Brine with Different Salinity for Reservoir Cores. SPE Annu. Tech. Conf. Exhib. 2007. [CrossRef]

9. Zhang, Y.; Morrow, N.R. Comparison of Secondary and Tertiary Recovery with Change in Injection Brine Composition for Crude-Oil/Sandstone Combinations. SPE/DOE Symp. Improv. Oil Recovery 2006. [CrossRef]

10. Tahir, M.; Hincapie, R.E.; Foedisch, H.; Abdullah, H.; Ganzer, L. Impact of Sulphates Presence During Application of Smart Water Flooding Combined with Polymer Flooding. SPE Eur. Featured 80th EAGE Conf. Exhib. 2018. [CrossRef]

11. Tay, A.; Oukhemanou, F.; Wartenberg, N.; Moreau, P.; Guillon, V.; Delbos, A.; Tabary, R. Adsorption Inhibitors: A New Route to Mitigate Adsorption in Chemical Enhanced Oil Recovery. SPE Asia Pac. Enhanc. Oil Recovery Conf. 2015. [CrossRef]

12. Zhang, P.; Tweheyo, M.T.; Austad, T. Wettability alteration and improved oil recovery by spontaneous imbibition of seawater into chalk: Impact of the potential determining ions $\mathrm{Ca}^{2+}, \mathrm{Mg}^{2+}$, and $\mathrm{SO}_{4}{ }^{2-}$. Colloids Surf. A Physicochem. Eng. Asp. 2007, 301, 199-208. [CrossRef]

13. Zhang, P.; Tweheyo, M.T.; Austad, T. Wettability Alteration and Improved Oil Recovery in Chalk: The Effect of Calcium in the Presence of Sulfate. Energy Fuels 2006, 20, 2056-2062. [CrossRef]

14. Gomari, K.A.R.; Hamouda, A.A.; Denoyel, R. Influence of sulfate ions on the interaction between fatty acids and calcite surface. Colloids Surf. A Physicochem. Eng. Asp. 2006, 287, 29-35. [CrossRef]

15. Karoussi, O.; Hamouda, A.A. Imbibition of Sulfate and Magnesium Ions into Carbonate Rocks at Elevated Temperatures and Their Influence on Wettability Alteration and Oil Recovery. Energy Fuels 2007, 21, 2138-2146. [CrossRef]

16. Tahir, M.; Hincapie, R.E.; Gaol, C.; Saefken, S.; Ganzer, L. Describing the Flow Behavior of Smart Water in Micromodels with Wettability Modified Pore Structures. Soc. Pet. Eng. 2020. [CrossRef]

17. Garcia-Olvera, G.; Alvarado, V. Interfacial rheological insights of sulfate-enriched smart-water at low and high-salinity in carbonates. Fuel 2017, 207, 402-412. [CrossRef]

18. Al-Saedi, H.N.; Flori, R.E.; Al-Jaberi, S.K. Eliminate the role of clay in sandstone: EOR low salinity water flooding. J. Petrol. Explor. Prod. Technol. 2019, 9, 1475-1483. [CrossRef]

19. Mohamed, M.I.; Alvarado, V. Smart Water Flooding in Berea Sandstone at Low Temperature: Is Wettability Alteration the Sole Mechanism at Play? SPE Annu. Tech. Conf. Exhib. 2017. [CrossRef]

20. Sullivan, A.P.; Zaki, N.N.; Sjöblom, J.; Kilpatrick, P.K. The Stability of Water-in-Crude and Model Oil Emulsions. Can. J. Chem. Eng. 2007, 85, 793-807. [CrossRef]

21. Czarnecki, J.; Moran, K. On the Stabilization Mechanism of Water-in-Oil Emulsions in Petroleum Systems. Energy Fuels 2005, 19, 2074-2079. [CrossRef]

22. Verruto, V.J.; Kilpatrick, P.K. Water-in-Model Oil Emulsions Studied by Small-Angle Neutron Scattering: Interfacial Film Thickness and Composition. Langmuir 2008, 24, 12807-12822. [CrossRef] [PubMed]

23. Mahzari, P.; Sohrabi, M. Crude Oil/Brine Interactions and Spontaneous Formation of Micro-Dispersions in Low Salinity Water Injection. SPE Improv. Oil Recovery Symp. 2014. [CrossRef]

24. Morin, B.; Liu, Y.; Alvarado, V.; Oakey, J. A microfluidic flow focusing platform to screen the evolution of crude oil-brine interfacial elasticity. Lab Chip 2016, 16, 3074-3081. [CrossRef] [PubMed]

25. Sohrabi, M.; Mahzari, P.; Farzaneh, S.A.; Mills, J.R.; Tsolis, P.; Ireland, S. Novel Insights into Mechanisms of Oil Recovery by Use of Low-Salinity-Water Injection. SPE J. 2017, 22, 407-416. [CrossRef] 
26. Bagci, S.; Kok, M.V.; Turksoy, U. Effect of Brine Composition on Oil Recovery by Waterflooding. Pet. Sci. Technol. 2001, 19, 359-372. [CrossRef]

27. Lager, A.; Webb, K.J.; Black, C.J.J. Impact of Brine Chemistry on Oil Recovery. In Proceedings of the IOR 2007-14th European Symposium on Improved Oil Recovery, Cairo, Egypt, 22-24 April 2007. Available online: http://www.earthdoc.org/publication/publicationdetails/?publication=6195 (accessed on 11 June 2019).

28. Ligthelm, D.J.; Gronsveld, J.; Hofman, J.; Brussee, N.; Marcelis, F.; van der Linde, H. Novel Waterflooding Strategy by Manipulation of Injection Brine Composition. EUROPEC/EAGE Conf. Exhib. 2009. [CrossRef]

29. Webb, K.J.; Black, C.J.J.; Tjetland, G. A Laboratory Study Investigating Methods for Improving Oil Recovery in Carbonates. Int. Pet. Technol. Conf. 2005. [CrossRef]

30. Yousef, A.A.; Al-Saleh, S.; Al-Jawfi, M.S. Smart WaterFlooding for Carbonate Reservoirs: Salinity and Role of Ions. SPE Middle East Oil Gas Show Conf. 2011. [CrossRef]

31. Suman, Y.K.; Shirif, E.; Ibrahim, H.; Ala-Ktiwi, A. “Evaluation of Low Saline Smart Water” Enhanced Oil Recovery in Light Oil Reservoirs. World J. Eng. Technol. 2013, 2, 13. [CrossRef]

32. Tahir, M.; Hincapie, R.E.; Foedisch, H.; Strobel, G.-J.; Ganzer, L. Potential Benefits of Fluid Optimization for Combined Smart-Water and Polymer Flooding: Impact on Remaining Oil Saturation. SPE Russ. Pet. Technol. Conf. 2019. [CrossRef]

33. Alvarado, V.; Wang, X.; Moradi, M. Role of Acid Components and Asphaltenes in Wyoming Water-in-Crude Oil Emulsions. Energy Fuels 2011, 25, 4606-4613. [CrossRef]

34. McGuire, P.L.; Chatham, J.R.; Paskvan, F.K.; Sommer, D.M.; Carini, F.H. Low Salinity Oil Recovery: An Exciting New EOR Opportunity for Alaska's North Slope. SPE West. Reg. Meet. 2005. [CrossRef]

35. Moradi, M.; Alvarado, V. Influence of Aqueous-Phase Ionic Strength and Composition on the Dynamics of Water-Crude Oil Interfacial Film Formation. Energy Fuels 2016, 30, 9170-9180. [CrossRef]

36. Nasralla, R.A.; Nasr-El-Din, H.A. Double-Layer Expansion: Is It a Primary Mechanism of Improved Oil Recovery by Low-Salinity Waterflooding? SPE Reserv. Eval. Eng. 2014, 17, 49-59. [CrossRef]

37. Bidhendi, M.M.; Garcia-Olvera, G.; Morin, B.; Oakey, J.S.; Alvarado, V. Interfacial Viscoelasticity of Crude Oil/Brine: An Alternative Enhanced-Oil-Recovery Mechanism in Smart Waterflooding. SPE J. 2018, 23, 803-818. [CrossRef]

38. AlGeer, M.A.; Gmira, A.; Al-Enezi, S.M.; Yousef, A.A. A New Insight on the Impact of Individual Ions on Fluid/Fluid Interactions and SmarWater Recovery. SPE EOR Conf. Oil Gas West Asia 2016. [CrossRef]

39. Garcia-Olvera, G.; Alvarado, V. The Potential of Sulfate as Optimizer of Crude Oil-Water Interfacial Rheology to Increase Oil Recovery During Smart Water Injection in Carbonates. SPE Improv. Oil Recovery Conf. 2016. [CrossRef]

40. Ayirala, S.C.; AlYousef, A.A.; Li, Z.; Xu, Z. Water Ion Interactions at Crude Oil-Water Interface: A New Fundamental Understanding on SmartWater Flood. SPE Middle East Oil Gas Show Conf. 2017. [CrossRef]

41. Zekri, A.; Al-Arabai, Z. An Experimental Investigation of Low Salinity Oil Recovery in Carbonate and Sandstone Formation|International Journal of Petroleum and Petrochemical Engineering. Available online: https://www.arcjournals.org/international-journal-of-petroleum-and-petrochemical-engineering/ volume-1-issue-1/1 (accessed on 15 April 2020).

42. Mamonov, A.; Puntervold, T.; Strand, S. EOR by Smart Water Flooding in Sandstone Reservoirs - Effect of Sandstone Mineralogy on Initial Wetting and Oil Recovery. Spe Russ. Pet. Technol. Conf. 2017. [CrossRef]

43. Al-Saedi, H.; Flori, R.E.; Mortadha, A. Investigation of Smart Water Flooding in Sandstone Reservoirs: Experimental and Simulation Study Part2. Abu Dhabi Int. Pet. Exhib. Conf. 2018. [CrossRef]

44. Reza, R. The Effect of Seawater on the Interfacial Tension: Smart Water Flooding. Available online: https://www.academia.edu/25203560/The_Effect_of_Seawater_on_the_Interfacial_Tension_Smart_Water_ Flooding (accessed on 15 April 2020).

45. Alotaibi, M.B.; Azmy, R.M.; Nasr-El-Din, H.A. Wettability Studies Using Low-Salinity Water in Sandstone Reservoirs. Offshore Technol. Conf. 2010. [CrossRef]

46. Shaker Shiran, B.; Skauge, A. Wettability and Oil Recovery by Low Salinity Injection. SPE EOR Conf. Oil Gas West Asia 2012. [CrossRef]

47. Havre, T.E.; Sjöblom, J. Emulsion stabilization by means of combined surfactant multilayer (D-phase) and asphaltene particles. Colloids Surf. A Physicochem. Eng. Asp. 2003, 228, 131-142. [CrossRef]

48. Horváth-Szabó, G.; Czarnecki, J.; Masliyah, J. Liquid Crystals in Aqueous Solutions of Sodium Naphthenates. J. Colloid Interface Sci. 2001, 236, 233-241. [CrossRef] 
49. Morrow, N.; Buckley, J. Improved Oil Recovery by Low-Salinity Waterflooding. J. Pet. Technol. 2011, 63, 106-112. [CrossRef]

50. Auflem, I.H.; Westvik, A.; Sjöblom, J. Destabilization of Water-in-Crude Oil Emulsions Based on Recombined Oil Samples at Various Pressures. J. Dispers. Sci. Technol. 2003, 24, 103-112. [CrossRef]

51. Kiran, S.K.; Acosta, E.J.; Moran, K. Evaluating the hydrophilic-lipophilic nature of asphaltenic oils and naphthenic amphiphiles using microemulsion models. J. Colloid Interface Sci. 2009, 336, 304-313. [CrossRef]

52. Anderson, W.G. Wettability Literature Survey- Part 1: Rock/Oil/Brine Interactions and the Effects of Core Handling on Wettability. J. Pet. Technol. 1986, 38, 1.125-1.144. [CrossRef]

53. Fathi, S.J.; Austad, T.; Strand, S. “Water-Based Enhanced Oil Recovery (EOR) by Smart Water”: Optimal Ionic Composition for EOR in Carbonates. Energy Fuels 2011, 25, 5173-5179. [CrossRef]

54. Aghaeifar, Z.; Strand, S.; Puntervold, T.; Austad, T.; Sajjad, F.M. Smart Water injection strategies for optimized EOR in a high temperature offshore oil reservoir. J. Pet. Sci. Eng. 2018, 165, 743-751. [CrossRef]

55. Luo, H.; Al-Shalabi, E.W.; Delshad, M.; Panthi, K.; Sepehrnoori, K. A Robust Geochemical Simulator to Model Improved-Oil-Recovery Methods. SPE J. 2016, 21, 55-73. [CrossRef]

56. Shaker Shiran, B.; Skauge, A. Enhanced Oil Recovery (EOR) by Combined Low Salinity Water/Polymer Flooding. Energy Fuels 2013, 27, 1223-1235. [CrossRef]

57. Sheng, J.J. Critical review of low-salinity waterflooding. J. Pet. Sci. Eng. 2014, 120, 216-224. [CrossRef]

58. Sheng, J.J.; Leonhardt, B.; Azri, N. Status of Polymer-Flooding Technology. J. Can. Pet. Technol. 2015, 54, 116-126. [CrossRef]

59. Mosalman Haghighi, O.; Mohsenatabar Firozjaii, A. An experimental investigation into enhancing oil recovery using combination of new green surfactant with smart water in oil-wet carbonate reservoir. J. Petrol. Explor. Prod. Technol. 2019. [CrossRef]

60. Hincapie, R.E. Pore-Scale Investigation of the Viscoelastic Phenomenon during Enhanced Oil Recovery (EOR) Polymer Flooding through Porous Media; Papierflieger: Clausthal-Zellerfeld, Germany, 2016.

61. Gaol, C.; Wegner, J.; Ganzer, L.; Dopffel, N.; Koegler, F.; Borovina, A.; Alkan, H. Investigation of Pore-Scale Mechanisms of Microbial Enhanced Oil Recovery MEOR Using Microfluidics Application. SPE Eur. Featured 81st EAGE Conf. Exhib. 2019. [CrossRef]

62. Hauhs, F.; Födisch, H.; Hincapie, R.E.; Ganzer, L. Novel Evaluation of Foam and Immiscible Gas Flooding in Glass-Silicon-Glass Micromodels. SPE Eur. Featured 80th EAGE Conf. Exhib. 2018. [CrossRef]

63. Schumi, B.; Clemens, T.; Wegner, J.; Ganzer, L.; Kaiser, A.; Hincapie, R.E.; Leitenmueller, V. Alkali/Cosolvent/ Polymer Flooding of High-TAN Oil: Using Phase Experiments, Micromodels, and Corefloods for Injection-Agent Selection. SPE Reserv. Eval. Eng. 2019. [CrossRef]

64. Moustafa, E.-A.A.A.; Shedid, S.A. Effects of magnesium and potassium sulfates on oil recovery by water flooding. Egypt. J. Pet. 2018, 27, 649-656. [CrossRef] 